\title{
Connections of Inferior Temporal Areas TE and TEO with Medial Temporal-Lobe Structures in Infant and Adult Monkeys
}

\author{
M. J. Webster, L. G. Ungerleider, and J. Bachevalier \\ Laboratory of Neuropsychology, National Institute of Mental Health, Bethesda, Maryland 20892
}

As part of a long-term study designed to examine the ontogeny of visual memory in monkeys and its underlying neural circuitry, we have examined the connections between inferior temporal cortex and medial temporal-lobe structures in infant and adult monkeys. Inferior temporal cortical areas TEO and TE were injected with WGA conjugated to HRP and tritiated amino acids, respectively, or vice versa, in 1-weekold and 3-4-yr-old Macaca mulatta, and the distributions of labeled cells and terminals were examined in both limbic structures and temporal-lobe cortical areas. In adult monkeys, inferior temporal-limbic connections included projections from area TEO to the dorsal portion of the lateral nucleus of the amygdala and from area TE to the lateral and lateral basal nuclei; inputs to both areas TEO and TE included those from the lateral, lateral basal, and medial basal nuclei of the amygdala and to area TE from the accessory basal nucleus. Additional limbic inputs to both areas TEO and TE arose from the posterior portion of the presubiculum. In infant monkeys, we found, in addition to these adultlike connections, a projection from area TEO to the lateral basal nucleus of the amygdala. Inferior temporal cortical connections in adult monkeys included projections from area TEO to area TE and, in turn, from area TE to area TG and perirhinal area 36, as well as from area TE back to area TEO; inputs to both areas TEO and TE included those from area TG, perirhinal areas 35 and 36 , and parahippocampal areas TF and TH. All of these adultlike connections were also observed in infant monkeys, but, in addition, the infants showed projections from area TE to perirhinal area 35 as well as to parahippocampal areas TF and TH, and from area TEO to area TF. Moreover, in infants, the projection from area TE to perirhinal area 36 was considerably more widespread than in adults, both in areal extent and in laminar distribution. The results therefore indicate the existence of projections in infant monkeys from inferior temporal areas to the amygdala, perirhinal cortex, and parahippocampal cortex that are either totally eliminated in adults or more refined in their distribu-

\footnotetext{
Received Aug. 21, 1990; revised Nov. 21, 1990; accepted Nov. 27, 1990.

We wish to thank Mortimer Mishkin for his advice and support during all phases of this work and for his comments on the manuscript. Skillful technical assistance was provided by John N. Sewell III, Thelma W. Galkin, and Joanna Lawrence. We also thank Howard Crawford for his assistance in surgery and Richard Duntz for supervising the care of the infant monkeys.

Correspondence should be addressed to Leslie G. Ungerleider, Laboratory of Neuropsychology, National Institute of Mental Health, Building 9, Room 1N107, Bethesda, MD 20892.

Copyright (C 1991 Society for Neuroscience $0270-6474 / 91 / 111095-22 \$ 03.00 / 0$
}

tion. Both elimination and refinement of projections thus appear to characterize the maturation of axonal pathways between the inferior temporal cortex and medial temporal-lobe structures in monkeys.

In the course of neural development, numerous mechanisms are at play to achieve the final configuration of the mature brain. These mechanisms include cell death, the growth of dendritic spines, and the remodeling of connections. Such remodeling can take 2 forms. In the first instance, projections become more restricted. That is, they initially terminate in the appropriate area of the brain, but their target fields are considerably more widespread in infancy than they will be later in adulthood. This kind of transient projection has been described for transcallosal pathways in several species, including the rat (Wise and Jones, 1976; Ivy et al., 1979; Ivy and Killackey, 1981, 1982; O'Leary et al., 1981; Cusick and Lund, 1982), rabbit (Chow et al., 1981), cat (Innocenti et al., 1977; Innocenti and Caminiti, 1980; Innocenti, 1981; Feng and Brugge, 1983), and monkey (Killackey and Chalupa, 1986; Berland et al., 1987). In the second instance, projections are totally eliminated. That is, they initially terminate in an anomalous area of the brain but then retract during development. Such elimination has been described for intrahemispheric projections (Dehay et al., 1984, 1988; Innocenti and Clarke, 1984; Clarke and Innocenti, 1986), retinofugal projections (Bunt and Lund, 1981; O'Leary et al., 1983), and various cortical-subcortical projections (Distel and Hollander, 1980; Stanfield et al., 1982, 1987; Adams et al., 1983; Tolbert and Panneton, 1983; Stanfield and O'Leary, 1985; Dehay et al., 1987). Both the refincment and climination of projections are largely due to the pruning of collaterals from those axons that are maintained into adulthood (Innocenti, 1981; O'Leary et al., 1981; Ivy and Killackey, 1982; Stanfield et al., 1982; Stanfield, 1984; Stanfield and O'Leary, 1985).

As part of a long-term study designed to examine the ontogeny of visual memory in monkeys and its underlying neural circuitry, we have discovered that both refinement and elimination of projections characterize the maturation of axonal pathways between the inferior temporal cortex and medial temporal-lobe structures, pathways known to be important for visual memory in the adult (Mishkin, 1982; Mishkin and Phillips, 1990). Refinement occurs for those outputs from area TE to perirhinal cortex, which become more restricted in their target field. Elimination by total retraction occurs for those outputs from area TEO to the lateral basal amygdaloid nucleus (LB) as well as for those from both areas TE and TEO to parahippocampal cortex.

Brief reports of this work have appeared previously (Webster et al., 1988, 1989). 
Table 1. Tracer injected into inferior temporal areas TEO and TE in each of the infant and adult monkeys

\begin{tabular}{|c|c|c|c|c|c|}
\hline \multirow[b]{2}{*}{ Case } & \multirow{2}{*}{$\begin{array}{l}\text { Commis- } \\
\text { surotomy }\end{array}$} & \multicolumn{2}{|l|}{ Area TEO } & \multicolumn{2}{|l|}{ Area TE } \\
\hline & & Left & Right & Left & Right \\
\hline \multicolumn{6}{|c|}{ Infants } \\
\hline I-1 & No & WGA-HRP & & ${ }^{3} \mathrm{H}-\mathrm{AA}$ & \\
\hline $\mathrm{I}-2$ & Yes & ${ }^{3} \mathrm{H}-\mathrm{AA}$ & WGA-HRP & WGA-HRP & \\
\hline $\mathrm{I}-3$ & No & & & ${ }^{3} \mathrm{H}-\mathrm{AA}$ & \\
\hline $\mathrm{I}-4$ & No & & & ${ }^{3} \mathrm{H}-\mathrm{AA}$ & \\
\hline $\mathrm{I}-5$ & No & WGA-HRP & & ${ }^{3} \mathrm{H}-\mathrm{AA}$ & \\
\hline I-6 & No & ${ }^{3} \mathrm{H}-\mathrm{AA}$ & & & \\
\hline \multicolumn{6}{|l|}{ Adults } \\
\hline A-1 & No & WGA-HRP & & ${ }^{3} \mathrm{H}-\mathrm{AA}$ & \\
\hline A-2 & Yes & ${ }^{3} \mathrm{H}-\mathrm{AA}$ & WGA-HRP & WGA-HRP & ${ }^{3} \mathrm{H}-\mathrm{AA}$ \\
\hline A-3 & No & WGA-HRP & & ${ }^{3} \mathrm{H}-\mathrm{AA}$ & \\
\hline A-4 & No & ${ }^{3} \mathrm{H}-\mathrm{AA}$ & & WGA-HRP & \\
\hline$A-5$ & No & ${ }^{3} \mathrm{H}-\mathrm{AA}$ & & WGA-HRP & \\
\hline A- 6 & No & WGA-HRP & & ${ }^{3} \mathrm{H}-\mathrm{AA}$ & \\
\hline
\end{tabular}

\section{Materials and Methods}

Six infant and 6 adult monkcys (Macaca mulatta) were uscd. The infant monkeys weighed $400-600 \mathrm{gm}$ and received injections of tritiated amino acids ( $\left.{ }^{3} \mathrm{H}-\mathrm{AA}\right)$ and/or wheat germ agglutinin conjugated to horseradish peroxidase (WGA-HRP) in the first postnatal week (Table 1). The adult monkeys weighed 3-6 kg and were injected with the same tracers at 3$4 \mathrm{yr}$ of age. Inferior temporal areas TEO and TE were injected in a total of 5 hemispheres in the infant monkeys and in a total of 7 hemispheres in the adult monkeys. In 1 infant and 1 adult monkey, areas TEO and TE were injected in both hemispheres following section of the corpus callosum and anterior commissure, whereas in all other monkeys, unilateral injections were made.

Injections of inferior temporal areas TEO and TE. All surgeries were performed under aseptic conditions, as described previously (Bachevalier et al., 1990). In the infant monkeys, anesthesia was induced by an intramuscular injection of a 1:10 mixture of acepromazine and ketaminc hydrochloride, whereas in the adult monkeys, anesthesia was induced with ketamine hydrochloride $(10 \mathrm{mg} / \mathrm{kg}$, i.m.) followed by sodium pentobarbital (i.v.). In both cases, supplements of anesthetic drugs were administered throughout surgery as required. Body temperature was maintained between $35^{\circ}$ and $37^{\circ} \mathrm{C}$ by heating pads (circulating warm water) surrounding the animal, and heart and respiratory rates were monitored throughout surgery. For the commissurotomized monkeys, the cerebral midline was exposed through unilateral bone and dura flaps. After retraction of the medial aspect of the left hemisphere, the corpus callosum and anterior commissure were transected with a small-gauge glass sucker. Following the transection, the dura was sewn and the bone flap replaced.

Cortical areas TEO and TE were visualized by removing a section of the skull overlying the temporal lobe. Pressure injections were made using a 1- $\mu$ l Hamilton syringe with a beveled 27-gauge needle, which was guided into the appropriate cortical area with the aid of an operating microscope. An equal-parts mixture of tritiated proline [New England Nuclear; $\mathrm{L}-\left(2,3,4,5-{ }^{3} \mathrm{H}\right)$; specific activity, $\left.100-140 \mathrm{Ci} / \mathrm{mmol}\right]$ and tritiated leucine [New England Nuclear; $\mathrm{L}-\left(3,4,5-{ }^{3} \mathrm{H}(\mathrm{N})\right)$; specific activity, $100-140 \mathrm{Ci} / \mathrm{mmol}$ ] was injected into area TEO or TE. The labeled amino acids were reconstituted in $0.9 \%$ saline to a final concentration of 200 $\mu \mathrm{Ci} / \mu$ l. Three injections of ${ }^{3} \mathrm{H}-\mathrm{AA}$ were made $1 \mathrm{~mm}$ apart at a rate of $0.02 \mu \mathrm{l} / 2 \mathrm{~min}$ for a total volume of $0.2 \mu \mathrm{l} /$ injection. Five days later, a $5 \%$ solution of WGA-HRP in $0.9 \%$ saline was injected into either area TEO or TE, whichever was not injected in the initial surgery. The WGAHRP injections were administered at the same rate and in the same volume as the ${ }^{3} \mathrm{H}-\mathrm{AA}$ injections.

Following the injections, the dura was sutured and the wound closed in anatomical layers. Each monkey was then kept in an incubator until it had recovered completely from anesthesia. As a prophylactic measure against infection, Chloromycetin $(12 \mathrm{mg} / \mathrm{kg}$ orally for infant monkeys and $50 \mathrm{mg} / \mathrm{kg}$ i.m. for adult monkeys) was administered the day of surgery and for 5 or $6 \mathrm{~d}$ postsurgery. $\Lambda$ s a precaution against brain edema, dexamethasone phosphate $(0.5 \mathrm{mg} / \mathrm{kg}, \mathrm{i} . \mathrm{m}$.) was given on the day preceding surgery, and this treatment was continued for $5 \mathrm{~d}$ after surgery with progressive withdrawal of the drug.

Histological processing. Two days following the WGA-HRP injection (i.e., $7 \mathrm{~d}$ after the ${ }^{3} \mathrm{H}$-AA injection), each animal received a lethal dose of sodium pentobarbital and was perfused transcardially with $0.9 \%$ saline followed by $3 \%$ paraformaldehyde in $0.1 \mathrm{~m}$ phosphate buffer $(\mathrm{pH}$, 7.4 ) and finally by a solution of $5 \%$ glycerol in $0.1 \mathrm{M}$ phosphate buffer (pH, 7.4). The brain was blocked stereotaxically, removed from the skull, photographed, and stored in $20 \%$ glycerol in phosphate buffer at $4^{\circ} \mathrm{C}$ for $3-4 \mathrm{~d}$. The brain was then placed in 2-methylbutane at $-70^{\circ} \mathrm{C}$ until cut (see Rosene et al., 1986). Frozen sections, $50 \mu \mathrm{m}$ in thickness, were cut in the coronal plane. Every fifth section was processed for autoradiography according to the procedures of Cowan et al. (1972). These sections were mounted, dipped in Kodak NTB2 emulsion, and exposed at $4^{\circ} \mathrm{C}$ for 20 weeks. Subsequently, the autoradiographs were developed in Kodak D19, fixed, and counterstained with thionin. Adjacent sections $250 \mu \mathrm{m}$ apart were processed for WGA-HRP histochemistry according to a modified tetramethylbenzidine protocol (Gibson et al., 1984). One section every $1 \mathrm{~mm}$ was counterstained with thionin, whereas the remaining sections were coverslipped unstained. Anterograde and retrograde labeling was plotted onto enlarged photographs of the thionin-stained sections for subsequent analysis and reconstruction.

Two-dimensional reconstruction of the inferior temporal cortex. In each case, a 2-D reconstruction of the inferior temporal cortex was made from a wire model using serial sections spaced 1-2 $\mathrm{mm}$ apart (Gattass and Gross, 1981; Ungerleider and Desimone, 1986; see Fig. 5). The wires were bent around layer IV of the enlarged photographs of the thionin-stained sections, and marks were made on the wires at cytoarchitectonic borders and other landmarks. After the wire model was flattened, the labeled cells and terminals were transferred from the photographs to the flattened map along the appropriate section lines. Data from intervening sections were interpolated onto the map.

Nomenclature. Cortical areas in the temporal lobe (TEO, TE, TF, TG, and $\mathrm{TH}$ ) were defined mainly according to the criteria of von Bonin and Bailey (1947). In addition, we further subdivided the ventromedial part of area TE into perirhinal areas 35 and 36 based on the cytoarchitectonic description of Amaral and his colleagues (Amaral et al., 1987; Insausti et al., 1987). However, for the temporal pole we did not adopt their term, area 36p (Insausti et al., 1987), but instead retained the original term, area TG (von Bonin and Bailey, 1947). Also, based on the results of the recent physiological mapping study of TEO (Boussaoud et al., 1991), we placed the ventral border of this area farther 
medially than described in behavioral studies (Iwai and Mishkin, 1969; Mishkin, 1982; Mishkin and Phillips, 1990). The superior limit of area TEO and the caudal limit of area TF were not always reliably identified. Finally, the anteromedial portion of area TH (i.e., the entorhinal cortex) was assigned to area 28, based on the descriptions of Amaral et al. (1987) and Insausti et al. (1987).

The amygdaloid nuclei were defined according to the nomenclature of Turner et al. (1980), except that we included their claustral area of the amygdala within the lateral amygdaloid nucleus based on recent immunohistochemical (Amaral and Bassett, 1989; Amaral et al., 1989) and connectional (D. G. Amaral, personal communication) studies.

\section{Results}

In the present section, we first describe the connections of areas TEO and TE with limbic structures (amygdala and hippocampal formation) in infant monkeys and then compare them to those in adult monkeys. We next describe the projections from areas TEO and TE to other inferior and medial temporal cortical regions in infant and adult monkeys. Finally, we compare this pattern of afferents with the reciprocal pattern of efferents from inferior and medial temporal cortical regions to areas TEO and TE. The pattern of labeling in other regions of cortex and in subcortical structures will be described elsewhere.

\section{Inferior temporal-limbic connections}

\section{Area TEO-limbic connections}

Infant monkeys. In all 5 cases, the injection sites were of comparable size and position, caudal to the posterior middle temporal sulcus, below the superior temporal sulcus, and rostral to the inferior occipital sulcus, that is, confined to area TEO (Boussaoud et al., 1991). In cases I-2 and I-5, the injections were somewhat more extensive than in the other cases; in case I-2, the injection included the upper bank of the posterior middle temporal sulcus (see Fig. 16 $\mathrm{A}$ ), and in case I-5, the injection extended below this sulcus to border the lip of the lateral bank of the occipitotemporal sulcus. In most cases, the core of the injection site was restricted to the middle of the cortical layers. A photomicrograph illustrating a representative injection site is shown in Figure $1 A$.

In the 3 cases with WGA-HRP injections, retrogradely labeled cells were found throughout the lateral basal nucleus (LB) of the amygdala and also extended into the dorsal region of the medial basal nucleus (MB), as shown for case I- 2 in Figure $2 A$ and for case I- 1 in Figure $3 A$. In each of the 3 cases, anterogradely labeled terminals were also present in LB, but did not extend as far posteriorly as the labeled cells; in 2 of the 3 cases, additional anterograde label was found in the most dorsal part of the lateral nucleus (L). The presence of projections from TEO to LB and L was confirmed in cases I-2 and I-6, which received ${ }^{3} \mathrm{H}$-AA injections in area TEO. In both cases, the resulting anterograde label was located in $\mathrm{LB}$ and $\mathrm{L}$, within the middle third of the rostrocaudal extent of these nuclei (Figs. 2B, 3C).

Examination of the contralateral amygdala in the 3 cases without commissurotomy revealed a few retrogradely labeled cells in LB in one (case I-1) but not in the others, and an absence of anterograde label in all 3 cases.

In the hippocampus proper, we found no label. However, in all 3 cases with WGA-HRP injections, there were a few retrogradely labeled cells located in the deep layers of the most caudal part of the presubiculum. No anterograde label was apparent in the presubiculum in any case with either WGA-HRP or ${ }^{3} \mathrm{H}-\mathrm{AA}$ injections.

Adult monkeys. The TEO injection sites in the adult cases completely overlapped those in the infant cases (for cf., see Fig.
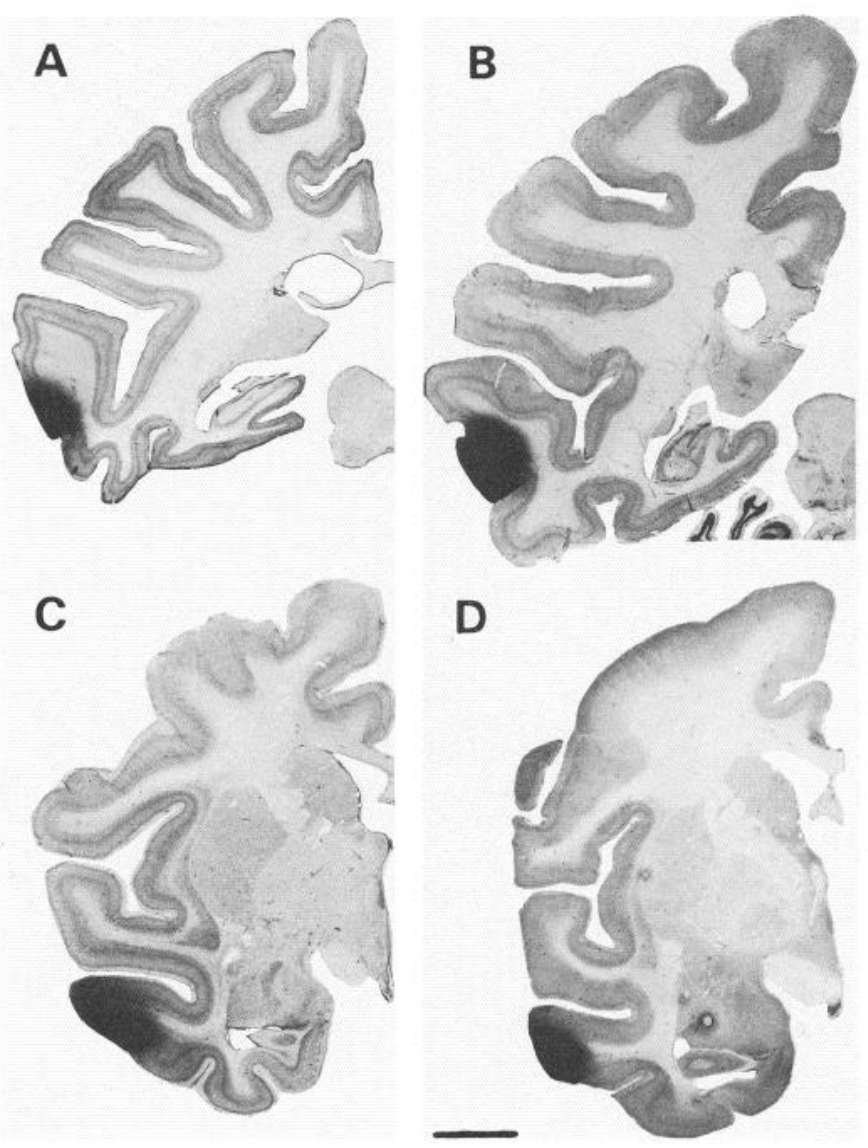

Figure 1. Representative ${ }^{3} \mathrm{H}-\mathrm{AA}$ injection sites in areas TEO and TE in infant and adult monkeys, shown on bright-field photomicrographs of thionin-stained coronal sections through the temporal lobe. $A$, Case I-6, TEO injection in an infant; $B$, case A-2, TEO injection in an adult; $C$, case I-5, TE injection in an infant; $D$, case A-3, TE injection in an adult. The small hole in the amygdala resulted from a fluorescent dye injection for the purpose of another study. Scale bar, $5 \mathrm{~mm}$ for $A-D$.

$1 A, B)$, and the pattern of retrograde labeling was highly similar. In all 4 adults injected with WGA-HRP, as in the infants, retrograde label in the amygdala was present in LB. In 2 of these cases (A-1 and A-2), there was a moderate number of retrogradely labeled cells throughout the rostrocaudal extent of LB (Figs. $2 C, 3 B$ ), whereas in the other 2 (cases A-3 and A-6), the cells were confined to the middle third of the nucleus. A few cells were also consistently found in MB. Unlike the finding in the infant monkeys, anterograde label in the adults was absent in LB. However, all 4 adult cases, like the infant cases, did show light anterograde label in the dorsal part of L (Figs. $2 C, 3 D$ ). Injections of ${ }^{3} \mathrm{H}-\mathrm{AA}$ in 3 additional cases (cases A-2, A-4, and A-5) confirmed an absence of projections from area TEO to LB in adults but failed to confirm the presence of projections from area TEO to L. In all adult cases, neither retrograde nor anterograde label was found in the contralateral amygdala.

Just as in the infant monkeys, in 3 of the 4 adults with WGAHRP injections, we found no label in the hippocampus proper but found labeled cells in the deep layers of the most caudal portion of the presubiculum. Again, in the adult monkeys, as in the infants, no anterograde label was found in either the hippocampus proper or the presubiculum. 


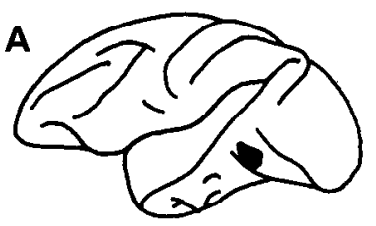

\section{TEO: Case I-2 (WGA-HRP)}
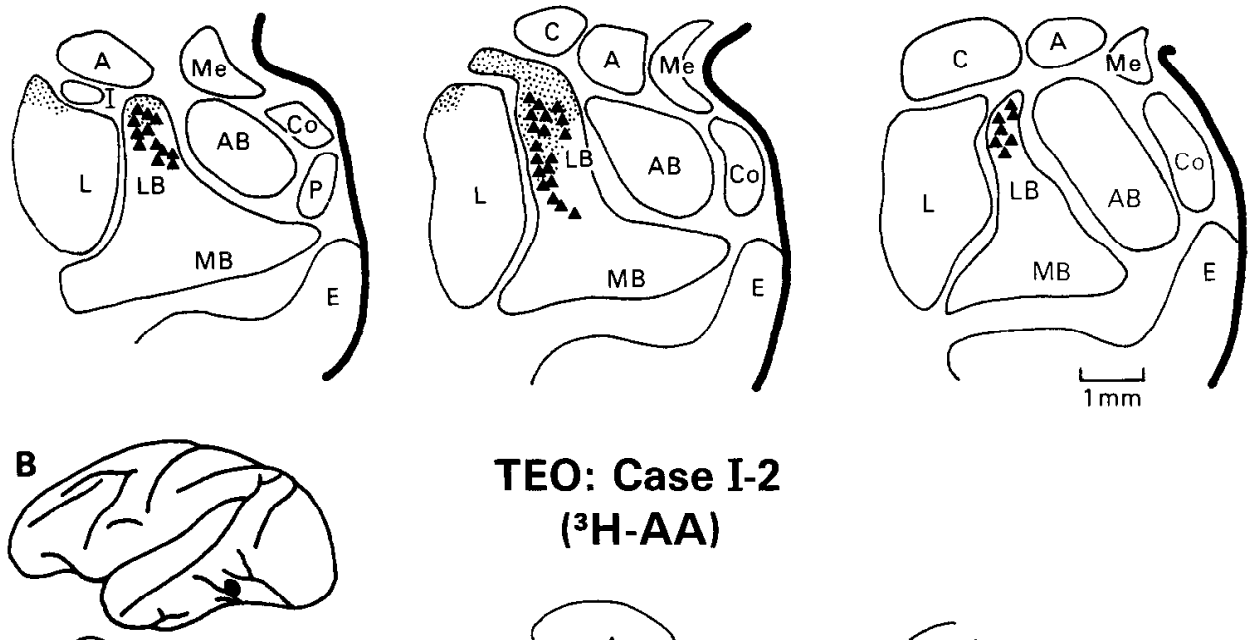

\section{TEO: Case I-2}

( $\left.{ }^{3} \mathrm{H}-\mathrm{AA}\right)$
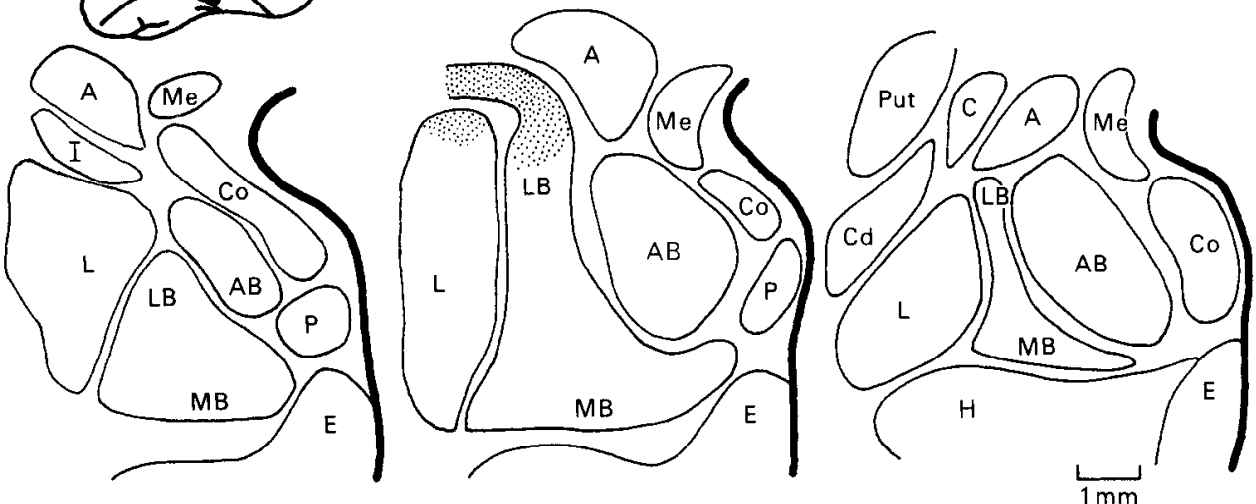

Figure 2. Location of area TEO injection sites in infant and adult monkeys and the distribution of the resulting label in the amygdala. Injection sites are shown in black on the lateral views of the hemisphere (top left of each panel). The distributions of retrogradely labeled cells (triangles) and anterogradely labeled terminals (small dots) are shown on coronal sections through the amygdala; sections from left to right indicate rostral to caudal levels. The thick solid line indicates the medial edge of the amygdala and the ventricular surface. $A$, Case I-2, WGA-HRP injection in an infant monkey; $B$, case $\mathrm{I}-2,{ }^{3} \mathrm{H}-\mathrm{AA}$ injection in an infant monkey; $C$, case A-1, WGA-HRP injection in an adult monkey. For abbreviations, see Appen-

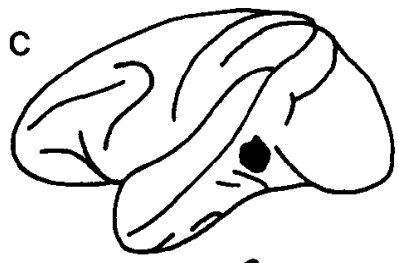

\section{TEO: Case A-1 (WGA-HRP)}
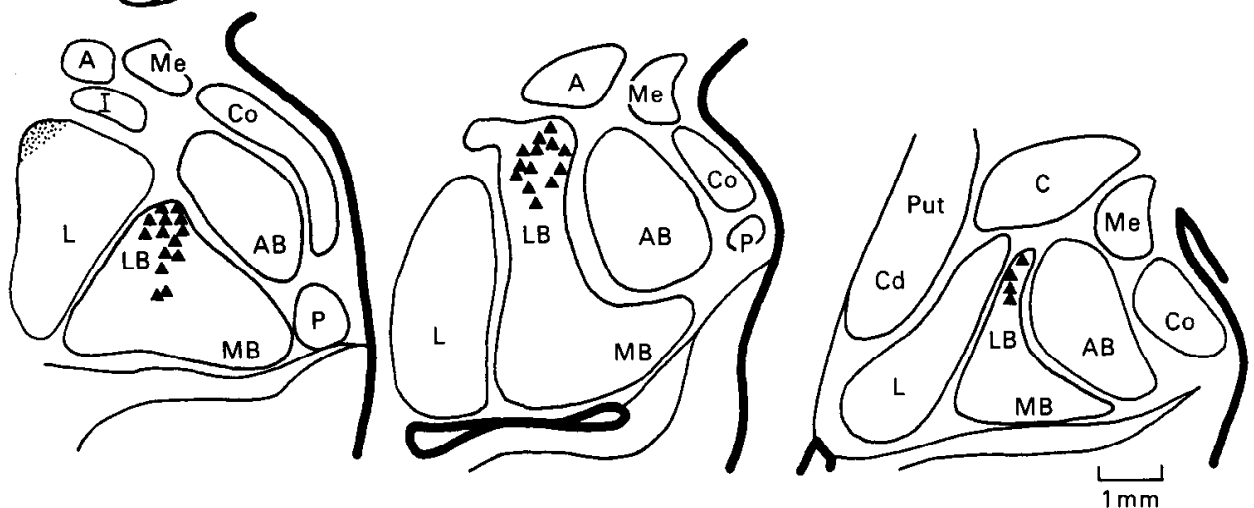
dix.

Figure 3. Dark-field photomicrographs illustrating the distribution of retrogradely labeled cells and anterogradely labeled terminals in the amygdala of infant and adult monkeys with area TEO injections. $A$, Case I-1, labeled cells and terminals in LB of the amygdala after a WGA-HRP injection in an infant; $B$, case A-1, labeled cells only in LB of the amygdala after a WGA-HRP injection in an adult; $C$, case I-2, labeled terminals in LB and the dorsal part of $\mathrm{L}$ of the amygdala after an ${ }^{3} \mathrm{H}-\mathrm{AA}$ injection in an infant; $D$, case A-6, labeled terminals in the dorsal part of $\mathrm{L}$ of the amygdala after an ${ }^{3} \mathrm{H}-\mathrm{AA}$ injection in an adult. Scale bars, $250 \mu \mathrm{m}$. 

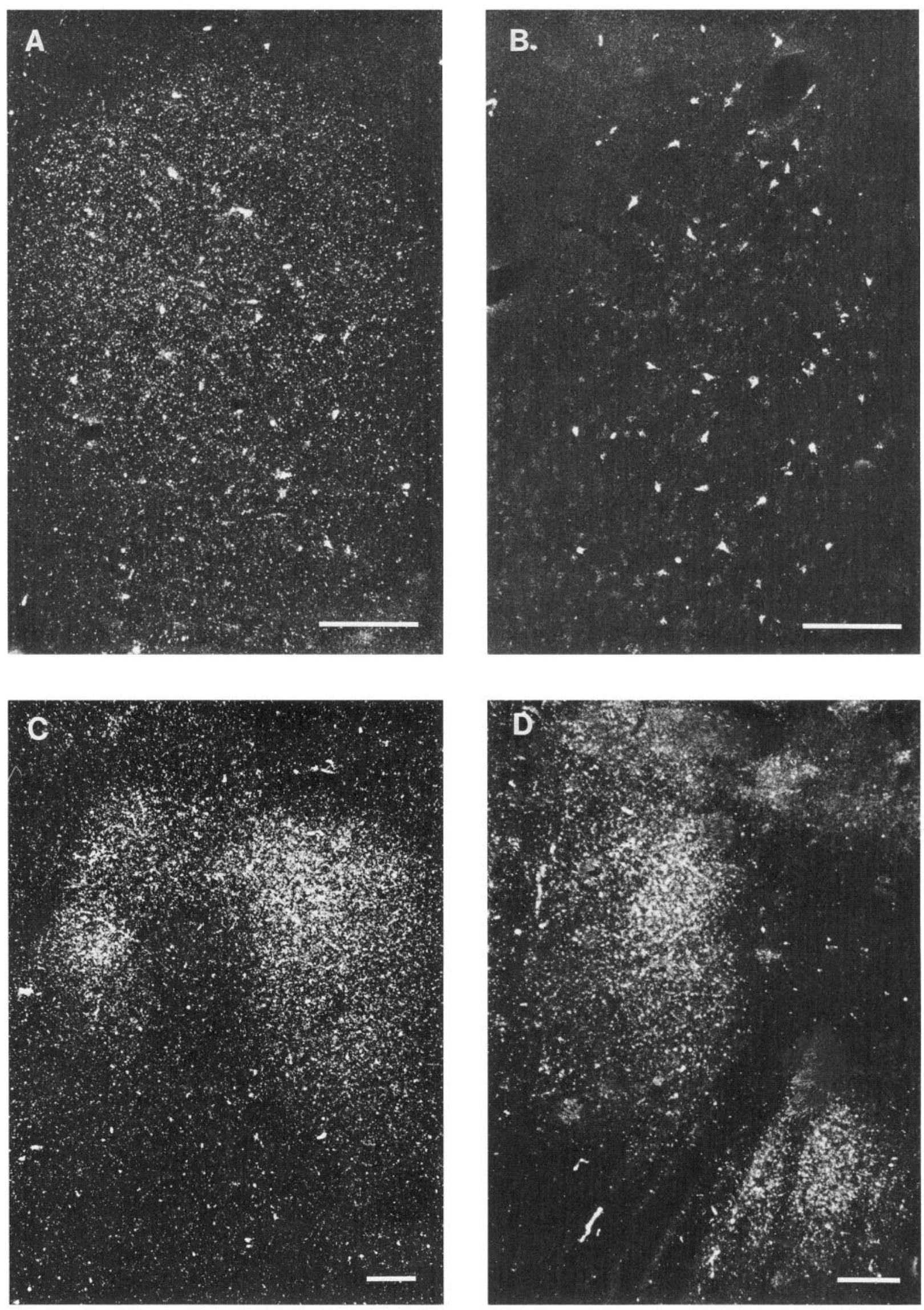

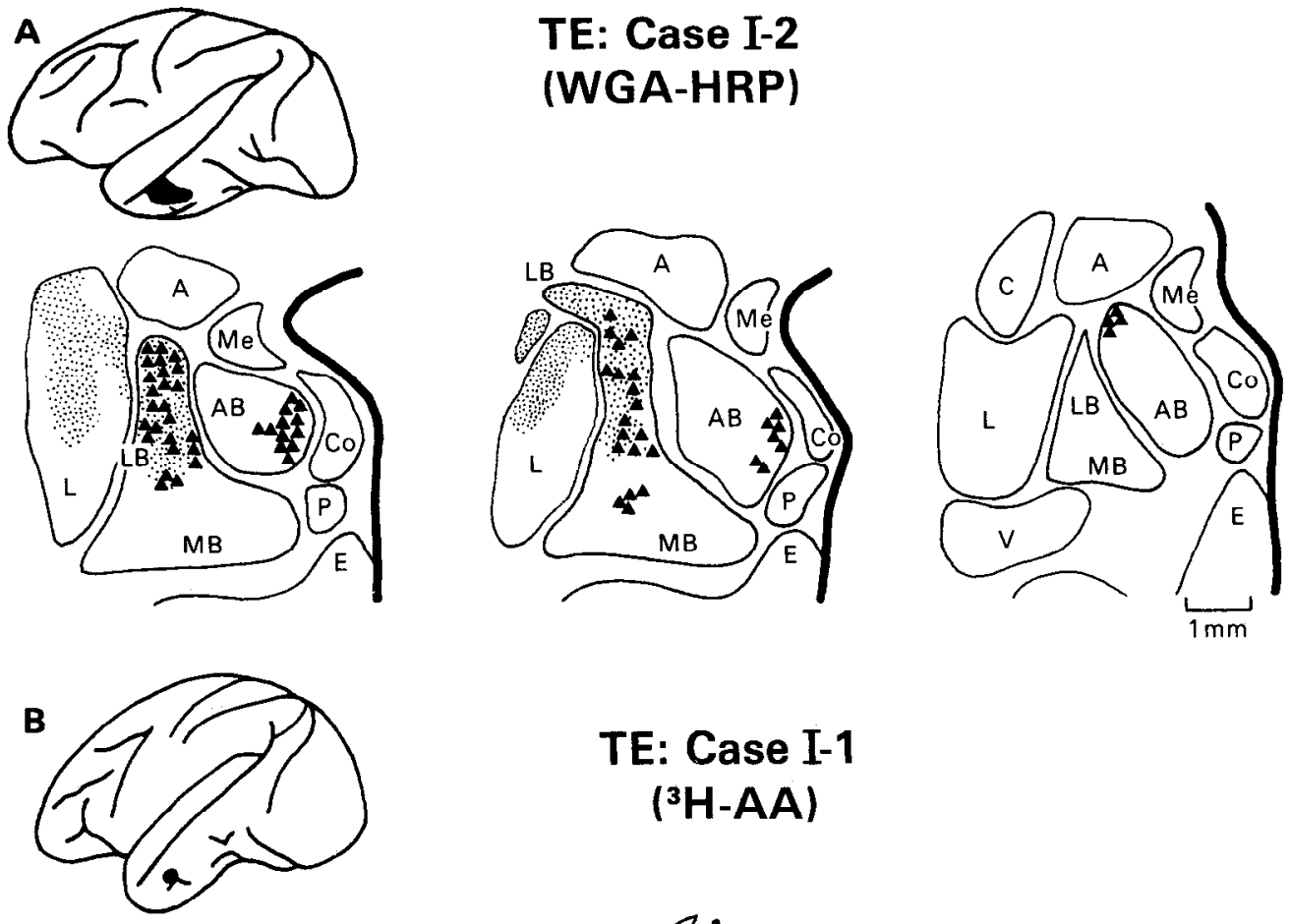

\section{TE: Case I-1 \\ ('H-AA)}

Figure 4. Location of area TE injection sites in infant and adult monkeys and the distribution of the resulting label in the amygdala. The thick solid line indicates the medial edge of the amygdala. Other conventions are as in Figure 2. $A$, Case I-2, WGA-HRP injection in an infant monkey; $B$, case $\mathrm{I}-1,{ }^{3} \mathrm{H}-\mathrm{AA}$ injection in an infant monkey; $C$, case A-2, WGA-HRP injection in an adult monkey. For abbreviations, see Appendix.
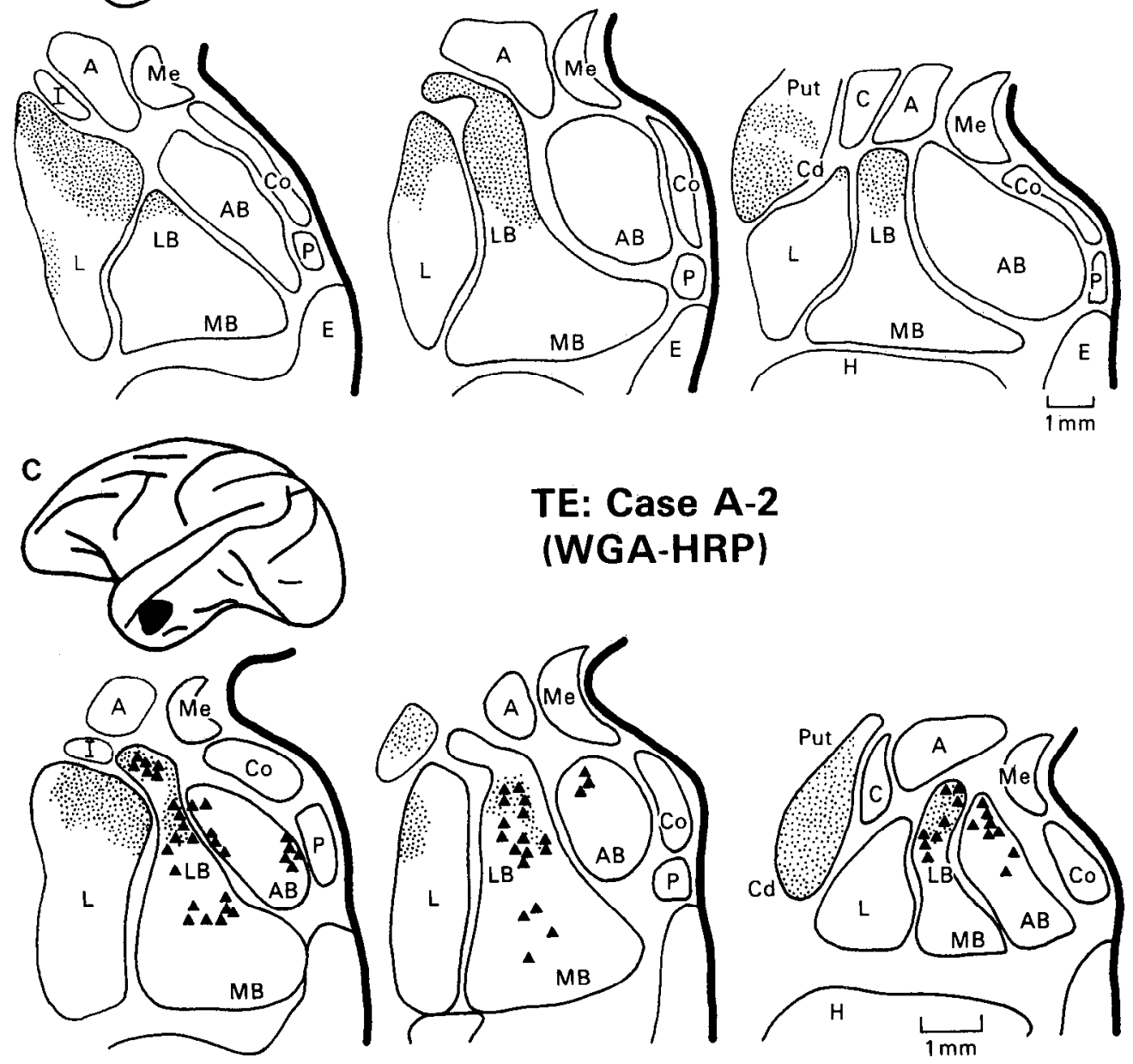

\section{Area TE-limbic connections}

Infant monkeys. The injections into area TE were placed in the dorsal half and middle third of the area, above the anterior middle temporal sulcus and below the superior temporal sulcus,

as shown for cases I-5 in Figure 1C. In case I-2, the WGA-HRP injection site also included a portion of the inferior bank of the superior temporal sulcus (see Figs. 4A, 17A).

In the 1 case with a WGA-HRP injection, case I-2, retrogradely labeled cells were found in several nuclei of the amygdala 


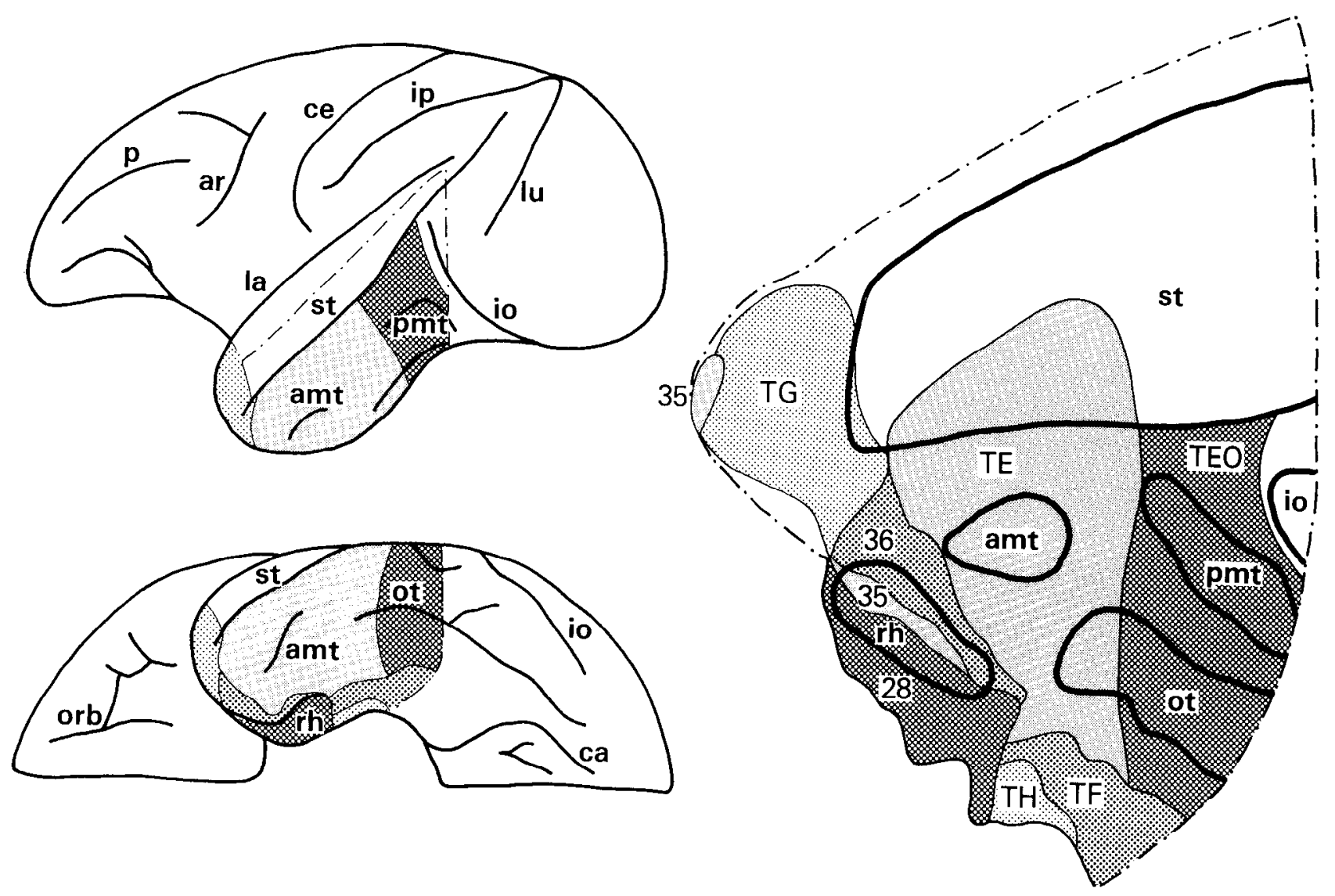

Figure 5. Locations and relative sizes of temporal lobe cortical areas plotted onto lateral and ventral views of the left hemisphere and on a 2-D reconstruction of the cortex ("flattened map"). The dot-dashed line on the lateral and ventral views indicates the region of cortex shown in the flattened map. Shaded regions indicate cytoarchitectonic areas, and borders of sulci are indicated by heavy lines. For abbreviations, see Appendix.

(Fig. 4A). A large number of cells was obscrved throughout LB, a moderate number throughout the accessory basal nucleus of the amygdala $(\mathrm{AB})$, and a few cells in MB. Anterograde label in this case was observed in both LB and L. The presence of projections from area TE to LB and $\mathrm{L}$ was confirmed in each of the 4 infant monkeys injected with ${ }^{3} \mathrm{H}$-AA. In each of these cases, we found a moderate amount of anterograde label throughout LB and heavy label in the dorsal portion of the anterior half of $\mathrm{L}$, as shown for case $\mathrm{I}-1$ in Figure $4 B$. In case I-3, light anterograde label was found additionally in AB (not illustrated).

Because the one case with a WGA-HRP injection also underwent commissurotomy, the presence or absence of retrograde labeling in the contralateral hemisphere could not be determined. In all 4 cases with ${ }^{3} \mathrm{H}-\mathrm{AA}$ injections, light anterograde label in the contralateral amygdala was found in the rostral and dorsal portion of $\mathrm{L}$.

Like TEO injections in infant and adult monkeys, the TE injection in case I-2 labeled cells in the deep layers of the caudal portion of the presubiculum. The part of the presubiculum labeled after the TE injection overlapped the zone labeled after the TEO injections. Anterograde label was never apparent in the presubiculum in any of the infant cases with TE injections. No label, either retrograde or anterograde, was found in the hippocampus proper.

Adult monkeys. The TE injection sites in the adult monkeys were comparable in relative size and extent to those in the infant monkeys, as illustrated for case A-3 (Fig. 1D), and the regions containing retrogradely labeled cells in the adults overlapped those seen in the infants.

Just as in the infant cases, in each of the 3 adult cases injected with WGA-HRP, we found in the amygdala a large number of cells throughout $\mathrm{LB}$, a moderate number in $\mathrm{AB}$, and a few in $\mathrm{MB}$, as shown for case A-2 in Figure $4 C$. The anterograde label in these cases, which also resembled that in the infants, was found in both $\mathrm{LB}$ and $\mathrm{L}$ (Fig. $4 C$ ). The presence of projections from area TE to $\mathrm{LB}$ and $\mathrm{L}$ was confirmed in the 4 cases with area TE injections of ${ }^{3} \mathrm{H}-\mathrm{AA}$. In each of these adult cases, we found a moderate amount of anterograde label throughout LB and heavy label in the dorsal portion of the anterior $2 / 3$ of $L$, which was similar to the distribution of labeling in the infant cases. Like the infant cases, the adults showed contralateral anterograde label in the rostrodorsal portion of $\mathrm{L}$. No retrograde label was found in the contralateral amygdala in any of the cases with WGA-HRP injections.

As in the infant cases, we observed retrogradely labeled cells in the deep layers of the caudal portion of the presubiculum, but only in 1 of the 3 adult cases injected with WGA-HRP. In this 1 adult case, the density of label in the presubiculum was comparable to that observed in the infant cases. No anterograde label was found in the presubiculum in any case, nor was there any label, anterograde or retrograde, in the hippocampus proper. 


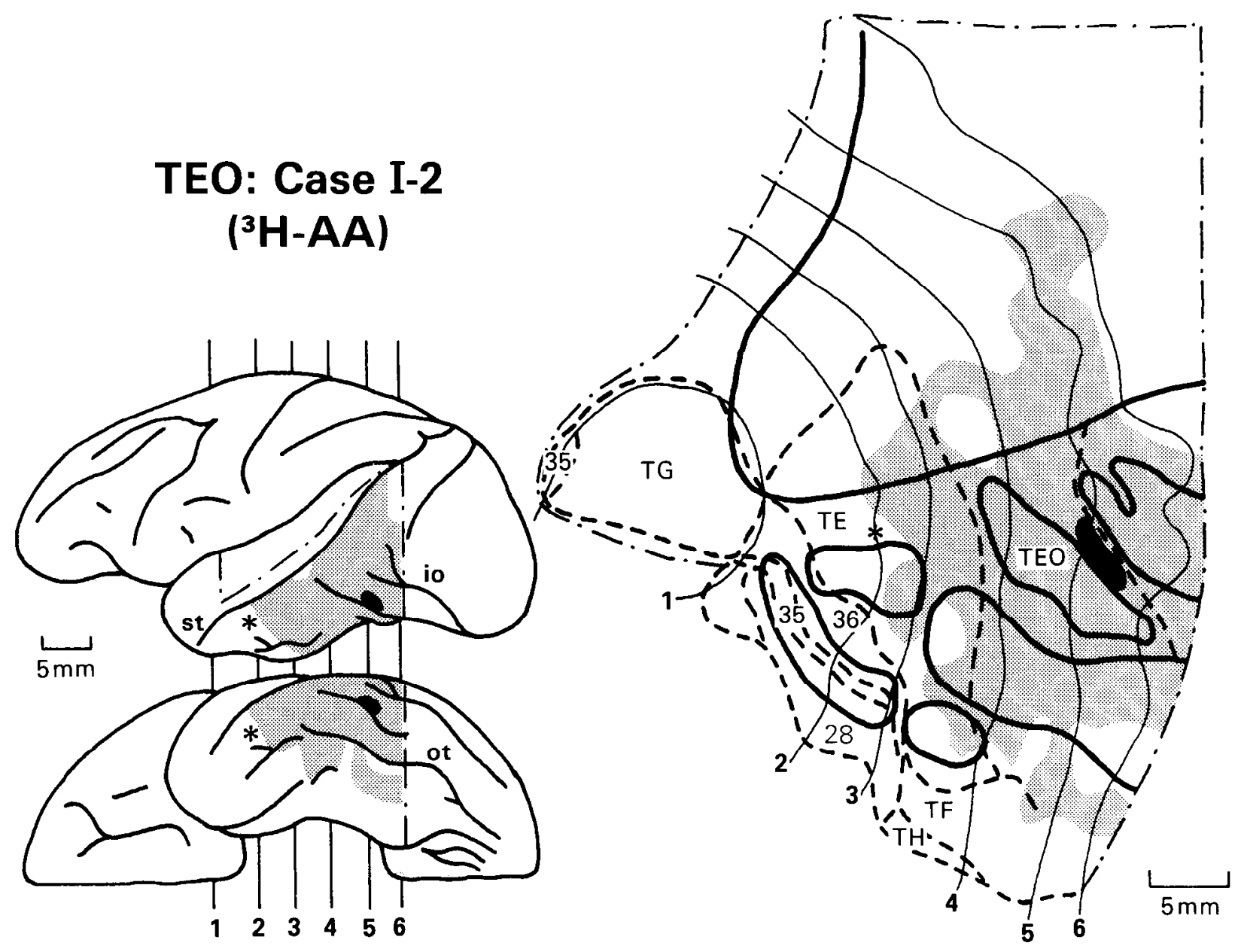

Figure 6. Case I-2: distribution of anterogradely labeled terminals following ${ }^{3} \mathrm{H}-\mathrm{AA}$ injection in area TEO of an infant monkey. The label is shown (shading) on lateral and ventral views of the hemisphere (left) and on a flattened map of the cortex (at right). Injection site is shown in black, and the asterisks indicate the site of a WGA-HRP injection in TE in the same hemisphere of this case. Heavy dashed lines indicate cytoarchitectonic borders. The thin lines running through the map indicate layer IV contour lines from selected coronal sections, whose locations are shown on the surface views of the hemisphere at the left. For all other conventions, see Figure 5.

\section{Inferior temporal-cortical connections}

The location and the relative sizes of the various temporal cortical areas are shown in Figure 5, both on a flattened map and on reconstructions of the lateral and ventral views of the brain. In the figures to follow, the location of the injection site and the extent of labeling are shown on flattened maps and reconstructions generated for each individual case and on selected cross sections. Cytoarchitectonic borders were determined independently for each case, as described above (scc Nomenclature, above).

We will first describe the pattern of anterograde labeling after injections of ${ }^{3} \mathrm{H}-\mathrm{AA}$ in areas TEO and TE for both infant and adult monkeys, and then the pattern of retrograde labeling after similar injections of WGA-HRP.

\section{Anterograde labeling after injections in area TEO}

Infant monkeys. Our analysis of the anterograde label was restricted to the ${ }^{3} \mathrm{H}-\mathrm{AA}$ data, because the anterograde WGA-HRP data were often masked by heavy background in the cortex. In the 2 infant monkeys that received injections of ${ }^{3} \mathrm{H}-\mathrm{AA}$ in area TEO (cases I-2 and I-6), labeled terminals were found throughout the remainder of area TEO, in the posterior $2 / 3$ of area TE, and in the inferior bank and floor of the superior temporal sulcus, as shown for case I-2 in Figure 6. In addition, in case I-2, the label extended farther ventromedially to include a small portion of area TF on the parahippocampal gyrus (see Fig. 6). We did not find label in perirhinal areas 35 or 36 , or in entorhinal area 28 .

In the region surrounding the injection site, label was distributed equally throughout the cortical layers. Rostral to the injection site, in area TE, label was heaviest in layer IV, whereas caudal to the injection site, in the posterior part of area TEO and in still more caudal regions, the label was heavier in layers I and V/VI. Medially, in area TF, label was found in all layers but was heaviest in layer IV (Fig. 7, section 5; see also Fig. 12A). Fig. 12A).

In the contralateral hemisphere, anterograde label was found throughout area TEO, extending dorsally into the inferior bank of the superior temporal sulcus and ventromedially into the occipitotemporal sulcus. The label was distributed in all cortical layers but was heaviest in layer IV.

Adult monkeys. Relative to the infant monkeys, in each of the 3 adult cases, only a restricted region of the inferior temporal cortex was labeled. As shown for case A-2 in Figure 8, label in the adults did not extend as far dorsally or as far medially as in 


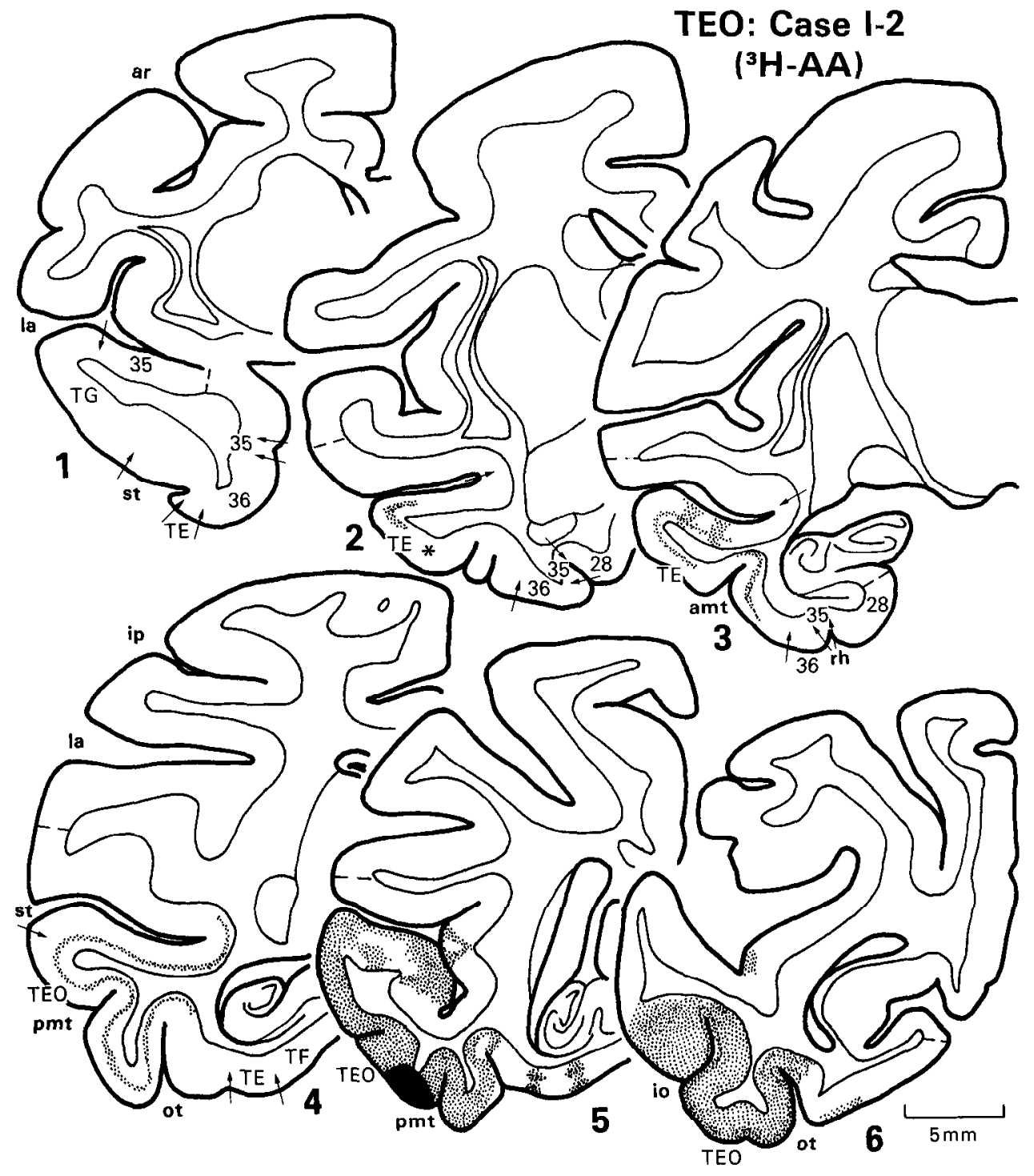

Figure 7. Case I-2: distribution of anterogradely labelcd tcrminals following ${ }^{3} \mathrm{H}-\mathrm{AA}$ injection in area TEO of an infant monkey. The label is shown (stippling) on selected coronal sections whose locations are indicated on the lateral and ventral views in Figure 6. The arrows on the sections indicate cytoarchitectonic borders, and the broken lines indicate the limits of the flattened map shown in Figure 6. For all other conventions, see Figures 5 and 6. the infants. In the adults, there was no label in area TF on the parahippocampal gyrus, and only small portions of the superior temporal and occipitotemporal sulci were labeled. As in the infants, approximately the posterior $2 / 3$ of area TE was labeled in the adults, and there was no label in either perirhinal or entorhinal cortex. In all areas labeled in the adult cases, the laminar distribution was identical to that found in the infant cases (Fig. 9).

In the contralateral hemisphere, the label in the adults, as in the infants, was located in area TEO and was heaviest in layer IV. But, in contrast to the label in the infants, the label in the adults did not extend so far ventromedially as to include the occipitotemporal sulcus.

\section{Anterograde labeling after injections in area $T E$}

Infant monkeys. In each of the 4 infant monkeys injected with ${ }^{3} \mathrm{H}-\mathrm{AA}$ in area TE, heavy and extensive anterograde label was found throughout the inferior temporal cortex, including areas TEO, TE, and TG, as shown for case I-1 in Figure 10. In addition, the label extended dorsally into the inferior bank and floor of the superior temporal sulcus and medially into perirhinal area 36; in 1 case, I-1, the label also included area 35 (Fig. 10).
None of the cases showed label in entorhinal cortex. In each case, we also found label in parahippocampal area TF, and in 2 of the 4 cases, label was present in area $\mathrm{TH}$.

In the region surrounding the injection site, label was distributed throughout all cortical layers. Rostral to the injection site, in the more anterior portions of area TE and in TG, label was present mainly in layer IV, whereas caudal to the injection site, in area TEO, label was found predominantly in laycrs I and V/VI (Fig. 11). Medially, label was found in all layers of both perirhinal and parahippocampal cortex, including areas TF and TH, but it was heaviest in layers I and IV of perirhinal cortex (see Figs. 11, section 2;15A) and in layers I and V/VI of area TF (Figs. 11, section 5; 12B).

In the contralateral hemisphere, extensive anterograde label was found throughout area TE in each case, and in 2 of the 4 cases, it extended posteriorly into the rostral part of area TEO. The contralateral label was distributed throughout all cortical layers, but it was heaviest in layer IV in the most rostral sections and heaviest in layer $I$ in the most caudal sections.

Adult monkeys. Relative to the infant monkeys with area TE injections, each of the adults showed labeling in only a restricted region of the inferior temporal cortex. As shown for case A-3 
TEO: Case A-2 ('H-AA)

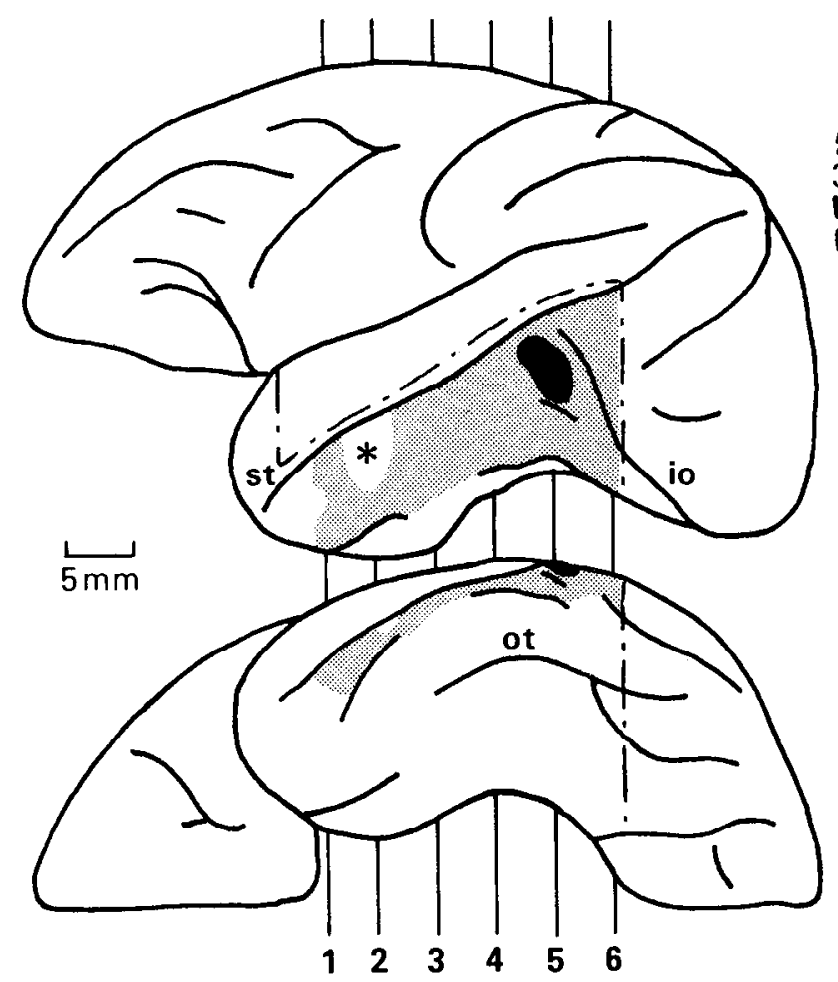

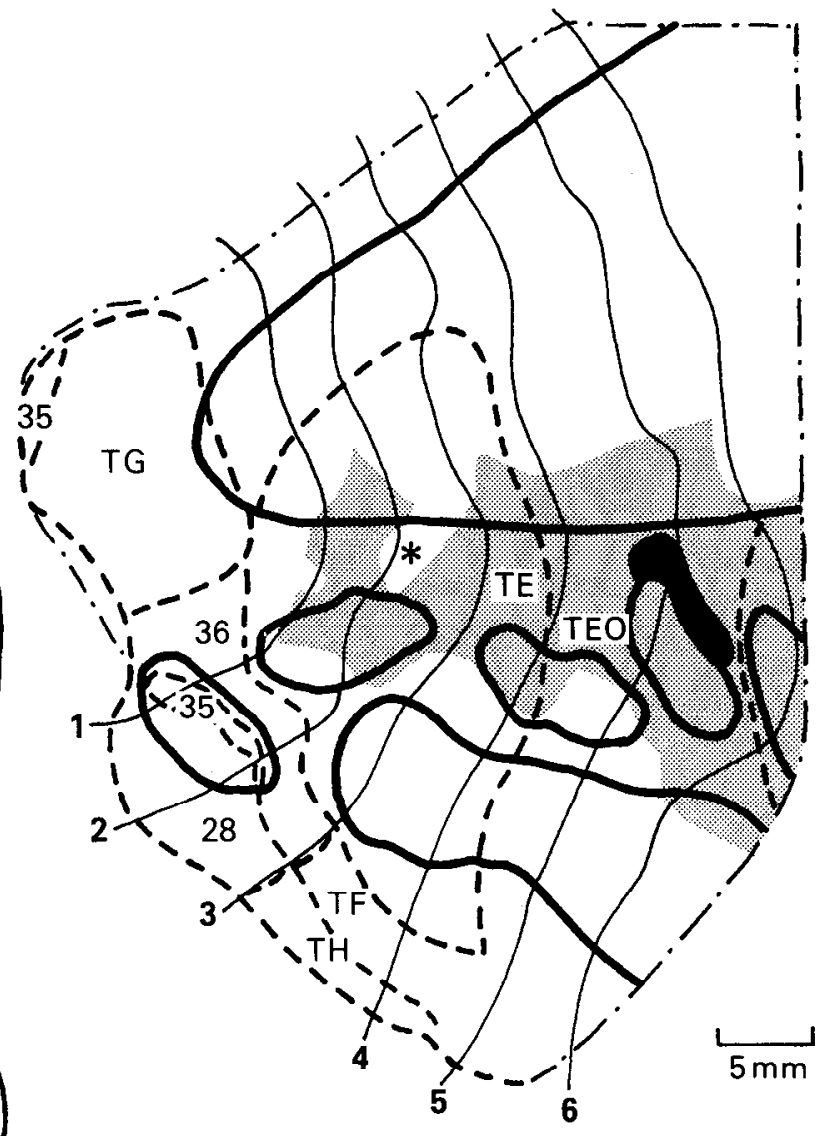

6

Figure 8. Case A-2: distribution of anterogradely labeled terminals following ${ }^{3} \mathrm{H}-\mathrm{AA}$ injection in area TEO of an adult monkey. All conventions are as in Figures 5 and 6.

in Figure 13, label in the adults, in both areas TEO and TE, did not extend as far dorsally or as far medially as in the infants. In the adults, the label was limited in the superior temporal sulcus to its inferior bank and in the occipitotemporal sulcus to its rostral tip. Moreover, there was an absence of label in the parahippocampal gyrus. Again, in contrast to the infants, in which label was apparent throughout the entire extent of perirhinal area 36 (Fig. 10), in each of the adults, the label was confined to a small region. Of the 4 adult cases, the case illustrated (case A-3) had the most extensive label in area 36 . The restricted labeling in adults relative to infants with area TE injections thus parallels the restricted labeling in adults relative to infants with area TEO injections. However, in several other ways the labeling in the adults with area TE injections resembled that in the infants. First, in the adults as in all of the infants, label was absent in entorhinal area 28. Second, in the adults as in 3 of the 4 infants, label was absent in perirhinal area 35 . Third, the labeling in area TG was comparable in the infants and in the adults.

The laminar pattern of anterograde labeling in the adults was also identical to that found in the infants, with 1 exception: In perirhinal area 36 , the label in the infants was heaviest in both layers I and IV, whereas heavy labeling in the adults was confined to layer IV (Figs. 14, section $2 ; 15 B$ ).

In the contralateral hemisphere, the label in the adults was confined to area TE (predominantly in layer IV) and was thus more limited than the contralateral label in the infants.

\section{Retrograde labeling after injections in area TEO}

Infant monkeys. In the 3 infant monkeys injected with WGAHRP in area TEO, we found retrograde label distributed, in general, over the same region of cortex that contained anterograde label in the infant monkeys injected with ${ }^{3} \mathrm{H}-\mathrm{AA}$ (for comparison, see Figs. $6,16 A$ ). However, in all 3 cases, cells were found throughout perirhinal area 36 , and in 2 of the 3 cases, cells were also found in the lateral part of area 35 ; by contrast, ncither arca 36 nor arca 35 containcd antcrograde labcl. In addition, in all 3 cases, cells were found throughout almost all of area TF, and in 2 of the 3 cases they were also present in area $\mathrm{TH}$; by contrast, only a small part of area TF and none of area $\mathrm{TH}$ contained anterograde label. No retrograde label was found in area TG.

In most cortical regions, the labeled cells were found in both layers III and V/VI, but in perirhinal and parahippocampal cortex, they were mainly in layer V/VI.

In the contralateral hemisphere, labeled cells were found throughout area TEO, similar to the region containing contralateral anterograde label, and were confined to layer III.

Adult monkeys. In the 4 adult monkeys with WGA-HRP injections, the distribution of retrograde label was far greater in 


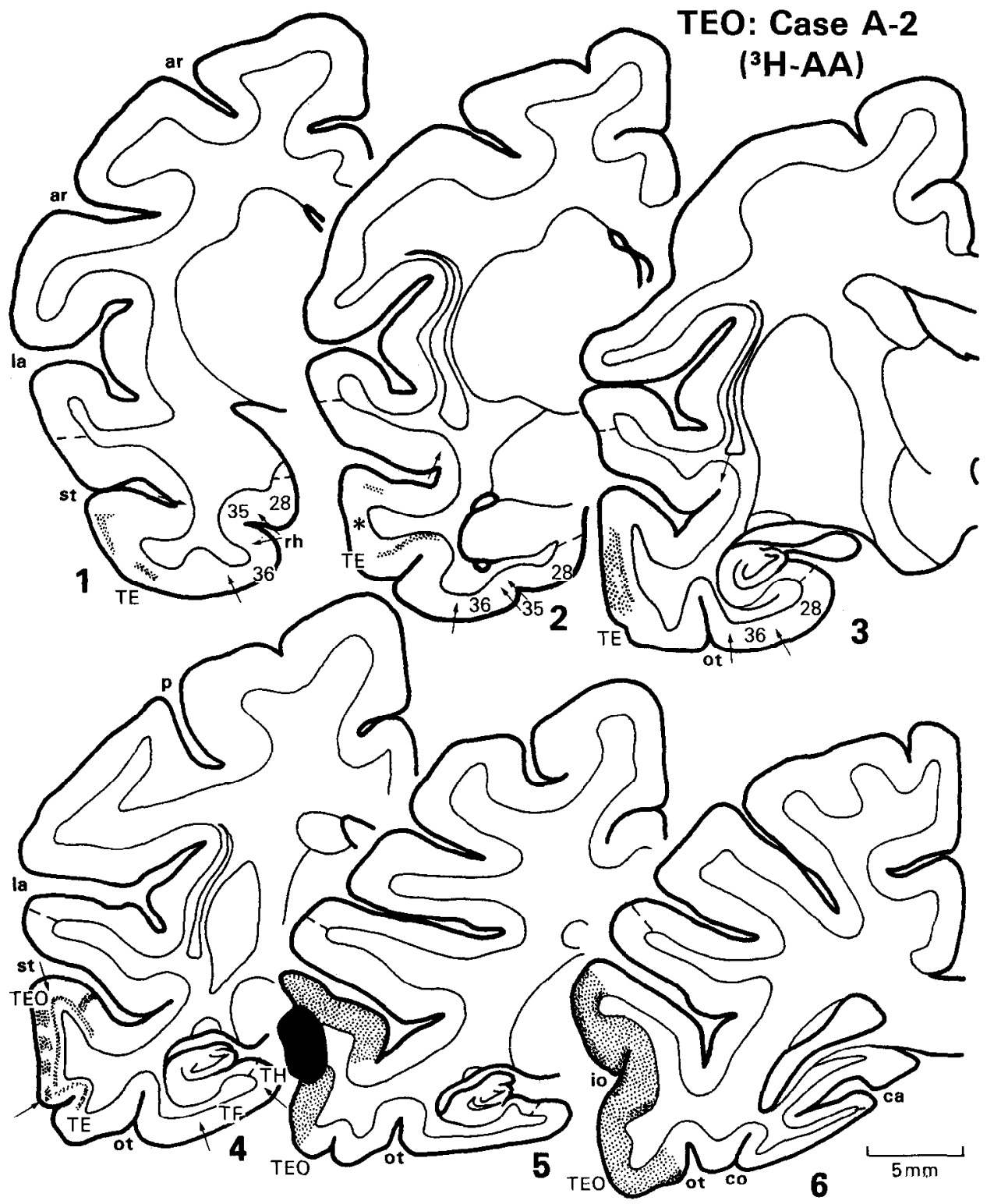

Figure 9. Case A-2: distribution of anterogradely labeled terminals following ${ }^{3} \mathrm{H}-\mathrm{AA}$ injection in area TEO of an adult monkey. The label is shown (stippling) on selected coronal sections whose locations are indicated on the lateral and ventral views in Figure 8. All conventions are as in Figures 5-7. extent than that of the anterograde label found in the adults with ${ }^{3} \mathrm{H}-\mathrm{AA}$ injections (for comparison, see Figs. 8, 16B). As illustrated for case A-2 in Figure $16 B$, labeled cells were found throughout areas TEO and TE, extending dorsally into the inferior bank and floor of the superior temporal sulcus and ventromedially into parahippocampal areas TF and TH. In addition, in all 4 cases, cells were found in perirhinal area 36 , and in 2 of the 4 cases, cells were found in area 35 . Finally, in 1 case (case A-2), area TG also contained labeled cells (see Fig. $16 B$ ). The region containing labeled cells in the adults was remarkably similar to the region containing labeled cells in the infants, and the laminar distribution of the retrograde labeling was identical in the adults and in the infants.

In the contralateral hemisphere, labeled cells were found throughout area TEO, similar to the region containing cells in the infants but greater in extent than the region containing anterograde label in the adults. As in the infants, the cells in the adults were confined to layer III.

\section{Retrograde labeling after injections in area $T E$}

Infant monkeys. In the 1 infant monkey (casc I-2) injccted with WGA-HRP in area TE, the pattern of retrograde labeling mirrored the pattern of anterograde labeling in each of the infant monkeys injected with ${ }^{3} \mathrm{H}-\mathrm{AA}$, without exception (for comparison, see Figs. 10, 17 A). In most cortical areas, labeled cells were distributed in both layers III and V/VI. However, just as after area TEO injections in infants, labeled cells in perirhinal areas and in area TF (but not in area TH) were found predominantly in layer V/VI. Retrogradely labeled cells in the contralateral hemisphere could not be studied bccause case I-2 underwent commissurotomy.

Adult monkeys. In the 3 adult monkeys with WGA-HRP injections, the distribution of retrograde label was far more extensive than that of the anterograde label found in the adults with ${ }^{3} \mathrm{H}$-AA injections (cf. Figs. 13, 17B). As illustrated for case $A-2$ in Figure $17 B$, labeled cells were found throughout areas 


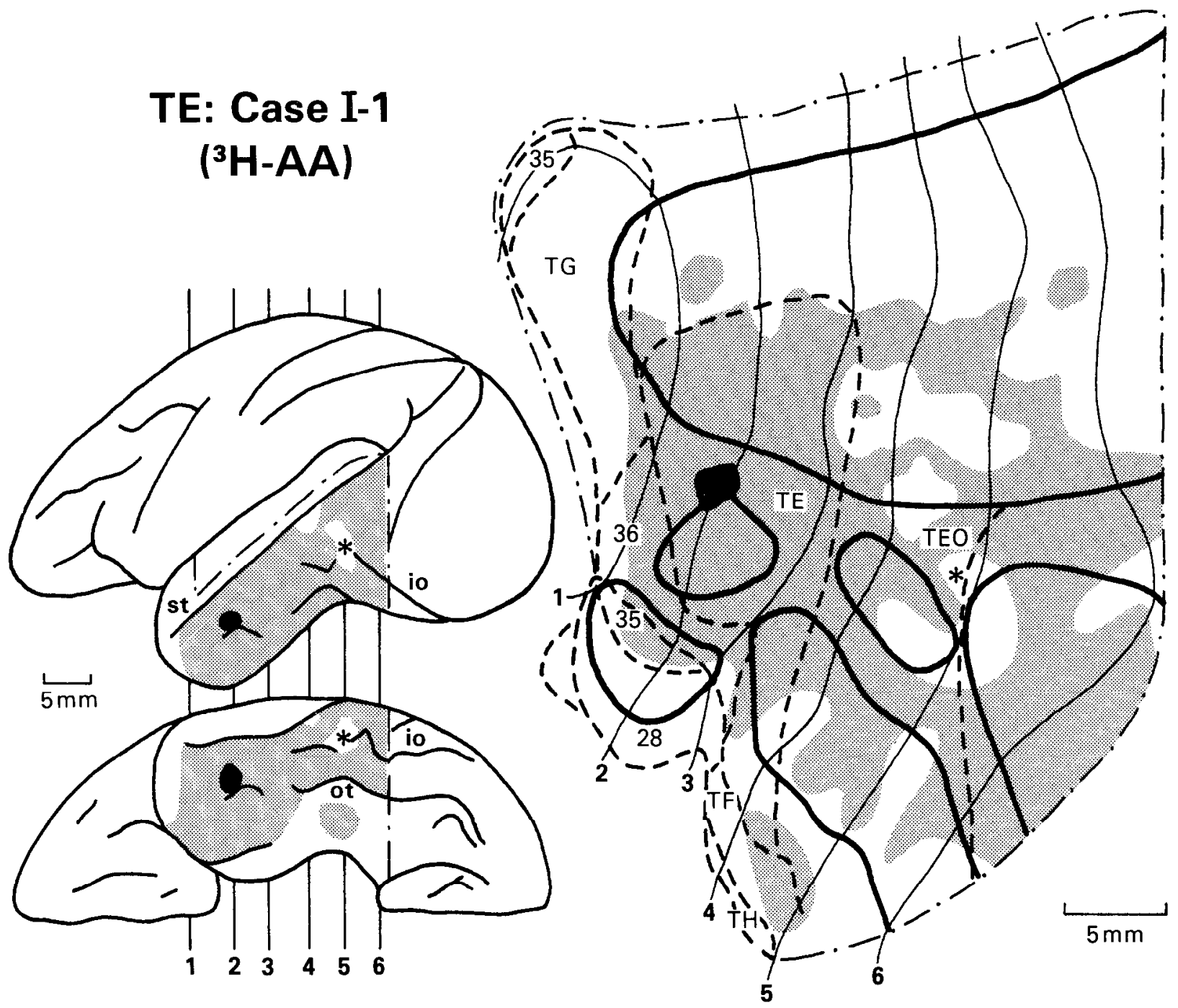

Figure 10. Case I-1: distribution of anterogradely labeled terminals following ${ }^{3} \mathrm{H}-\mathrm{AA}$ injection in area TE of an infant monkey. All conventions as in Figures 5 and 6.

TE and TEO, extending dorsally into the floor of the superior temporal sulcus and ventromedially into most of areas TF and TH. In addition, cells were found extensively in perirhinal area 36 and were present in area 35 as well. In area TG, the extent of retrograde and anterograde labeling was comparable. Both the region containing labeled cells and their laminar distributions were the same in the adults and the infants. Like the anterograde label in the contralateral hemisphere, contralateral label was found throughout area TE, with the filled cells being confined to layer III.

\section{Discussion}

The results of this study have revealed that both refinement and elimination of projections characterize the maturation of axonal pathways between the inferior temporal cortex and medial temporal-lobe structures in monkeys. First, a projection from area TEO to LB of the amygdala, which is present in infant monkeys, is absent in adult monkeys, indicating the retraction of this projection during development. Second, a projection from areas TEO and TE to parahippocampal cortex, also present in infant monkeys, is also absent in adult monkeys, again pointing to the retraction of a projection. Third, the projection from area TE to perirhinal areas, which is widespread in infant monkeys, becomes restricted in both areal extent and laminar distribution in adult monkeys, indicating the refinement of a projection. In the sections to follow, we first discuss the connections between the inferior temporal cortex and medial temporal-lobe structures in adult monkeys, comparing our results to those of previous investigations, and then we discuss our findings in infant monkeys. We then consider the laminar patterns of connections as they relate to a cortical hierarchy of information flow. Finally, we speculate on the functional significance of transient projections.

\section{Connections of inferior temporal cortex in adult monkeys}

Inferior temporal-limbic connections. We have found that area TE but not area TEO projects to LB and $\mathrm{L}$ of the amygdala. In addition, areas TEO and TE receive projections from $\mathrm{LB}, \mathrm{L}$, and $\mathrm{MB}$ of the amygdala, and TE also receives projections from $\mathrm{AB}$. These results thus confirm those of several previous studies (Aggleton et al., 1980; Turner et al., 1980; Amaral and Price, 1984; Iwai and Yukie, 1987; Iwai et al., 1987). We have also 


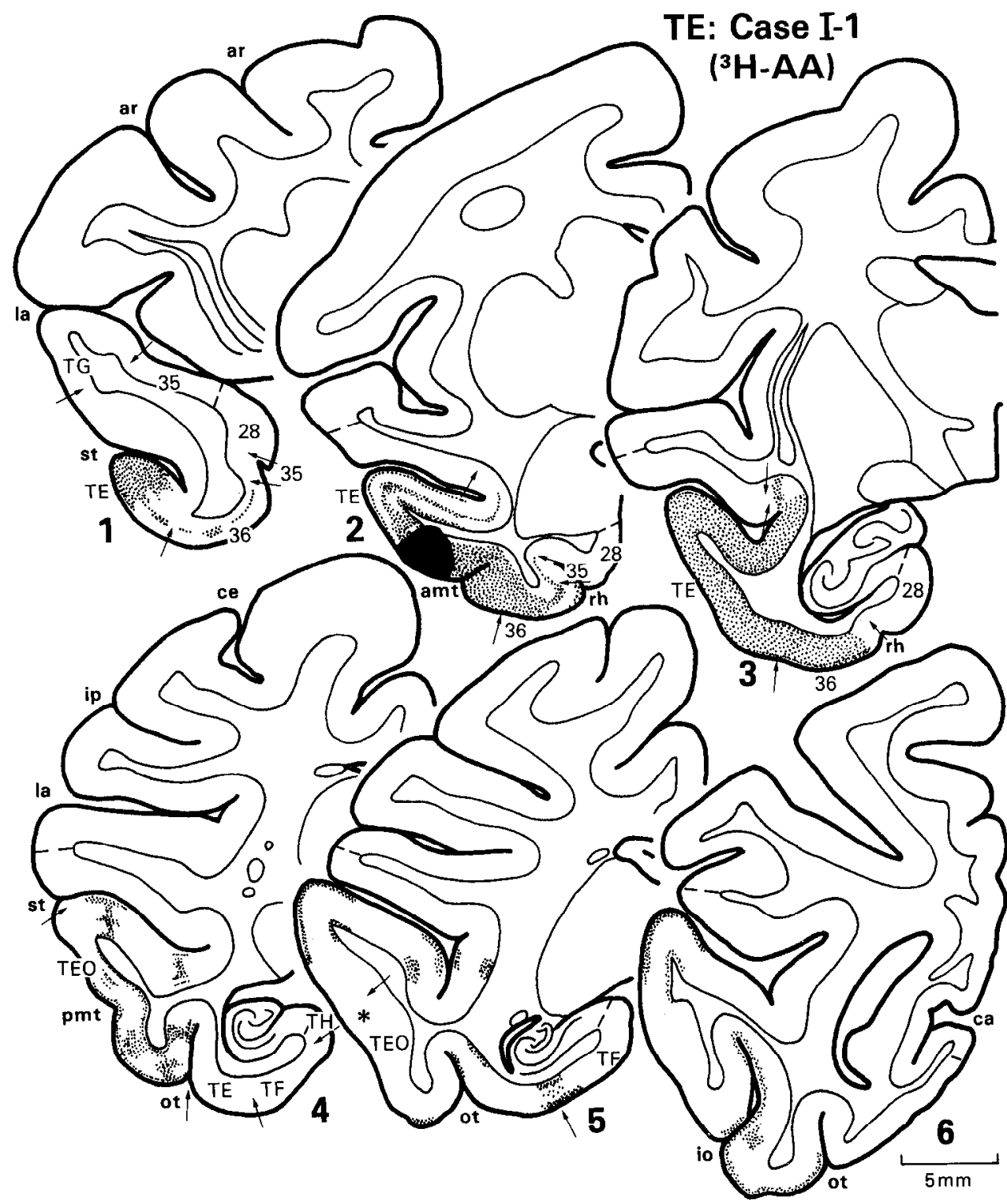

Figure 11. Case I-1: distribution of anterogradely labeled terminals following ${ }^{3} \mathrm{H}-\mathrm{AA}$ injection in area TE of an infant monkey. The label is shown (stippling) on selected coronal sections whose locations are indicated on the lateral and ventral views in Figure 10. All conventions are as in Figures 5-7. found, however, that area TEO sends a limited projection to the dorsal part of $\mathrm{L}$ of the amygdala. Although this finding has not been reported previously, Amaral has observed a similar projection in unpublished data (personal communication). In our study, the projection from area TEO to the dorsal part of $\mathrm{L}$ was present in all 4 cases with injections of WGA-HRP but in none of the 3 cases with injections of ${ }^{3} \mathrm{H}-\mathrm{AA}$, which is probably a reflection of the greater sensitivity of WGA-HRP (see Boussaoud et al., 1990).

We have also found a projection from area TE to the rostrodorsal portion of $\mathbf{L}$ of the contralateral amygdala, confirming the results of Iwai and Yukie (1987). This contralateral projection must be insufficient to sustain corticolimbic interactions, however, because crossed-lesion disconnection studies have shown that removal of area TE in one hemisphere and limbic structures in the other, but leaving the forebrain commissures intact, severely impairs visual recognition memory (Mishkin and Phillips, 1990).

Finally, we have found a projection to areas TE and TEO from the deep layers of the posterior portion of the presubicu- lum. Although earlier studies did not report labeling in the presubiculum after injections of areas TE or TEO (Desimone et al., 1980; Shiwa, 1987; Iwai and Yukie, 1988), Baizer et al. (1991) recently found such a projection.

Inferior temporal-cortical connections. The results from our anterograde tracing data indicate that, in adult monkeys, area TEO projects to area TE, and area TE, in turn, projects to areas TG and 36 and back to TEO. We did not find any projection from area TEO or TE to entorhinal area 28 or to parahippocampal areas TF and TH. On the whole, these results confirm those of previous studies using degeneration techniques (Jones and Powell, 1970; Van Hoesen and Pandya, 1975; Seltzer and Pandya, 1976). It is important to note that in our study the injections were always placed in the dorsal portions of areas TEO and TE. By contrast, in the earlier degeneration studies that investigated the connections of area TE, the lesions were large and generally extended beyond area TE as defined in this study; that is, they included area 36 . Thus, any discrepancies between the earlier studies and our study, particularly regarding the connections of area TE with parahippocampal areas, prob- 

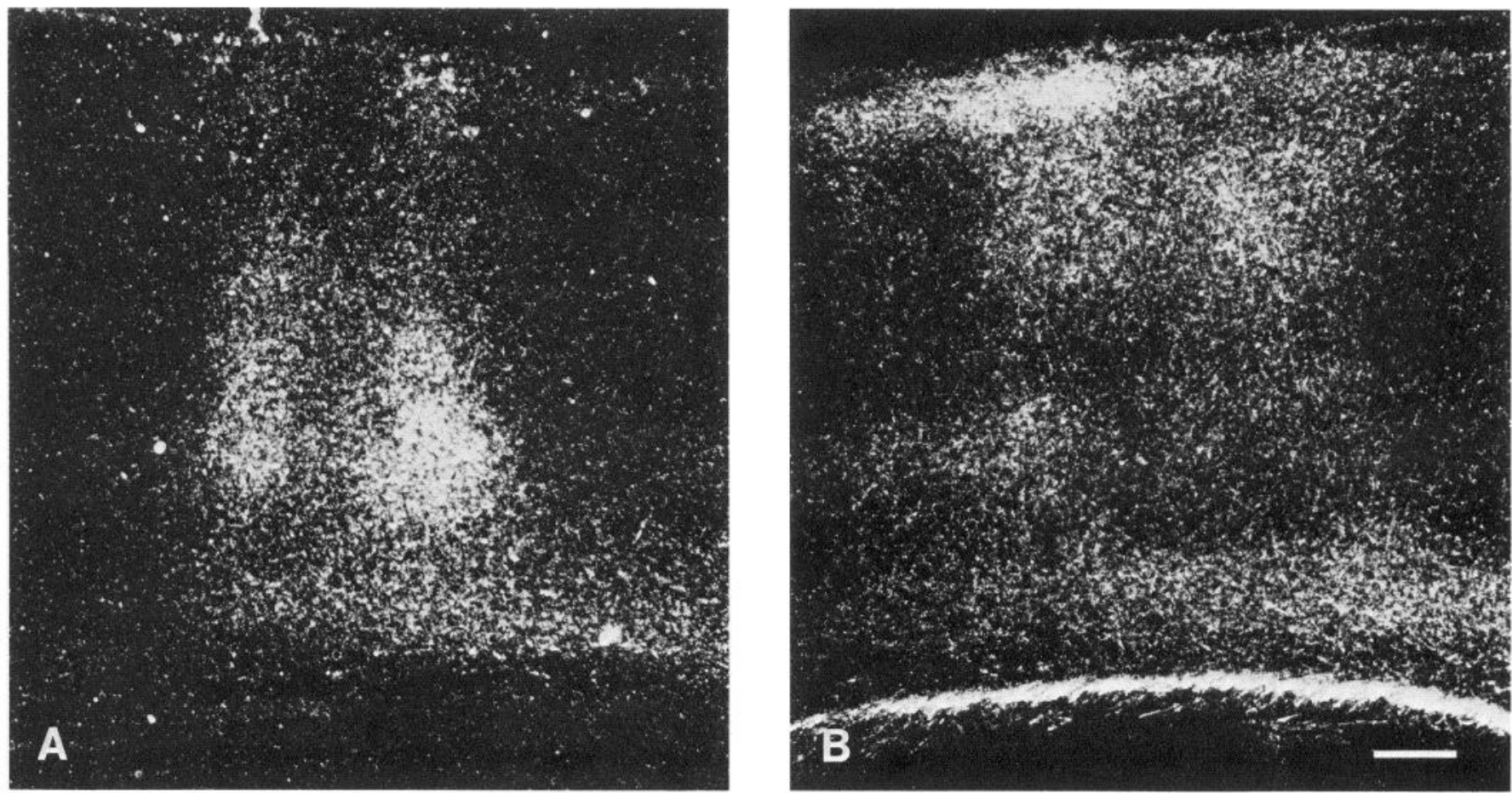

Figure 12. Dark-field photomicrographs illustrating anterogradely labeled terminals in parahippocampal area TF following ${ }^{3} \mathrm{H}-\mathrm{AA}$ injections in infant monkeys. $A$, Case I-2; label is mainly in layer IV after TEO injection. $B$, Case I-1; label avoids layer IV after TE injection. Scale bar, 250 $\mu \mathrm{m}$ for $A$ and $B$.

ably reflect differences between the connections of area TE and those of area 36.

The results from our retrograde tracing data indicate that both areas TEO and TE receive projections from area TG, perirhinal areas 35 and 36 , and parahippocampal areas TF and TH. In addition, areas TEO and TE receive projections from each other. Of the 2 previous studies that injected HRP into the dorsal portion of areas TEO and TE (Desimone et al., 1980; Shiwa, 1987), only 1 had shown labeled cells in perirhinal and parahippocampal areas (Shiwa, 1987). However, Van Hoesen (1980, 1982) has reported anterograde label in areas TEO and TE following injections of ${ }^{3} \mathrm{H}-\mathrm{AA}$ in parahippocampal areas, thus supporting our finding of inputs to areas TEO and TE from parahippocampal cortex. These results thus demonstrate an asymmetry between the inputs and outputs of areas TEO and TE. Area TEO receives projections from areas TG, TF, TH, 36, and 35, but does not project to these areas. Area TE receives projections from areas $\mathrm{TF}, \mathrm{TH}$, and 35 , but does not project to these areas. Thus, the region of cortex projecting into areas TEO and TE appears to be more widespread than the region of cortex receiving projections from these areas. This asymmetry between inputs and outputs may be a characteristic of this part of the brain, inasmuch as area TEO receives a projection from LB of the amygdala but does not project back to this nucleus, and areas TEO and TE both receive a projection from the presubiculum but do not project back to it. The implication of this finding is that areas that do not receive direct inputs from TEO and TE may nonetheless directly influence the processing of information within these areas.

\section{Connections of inferior temporal cortex in infant monkeys}

Inferior temporal-limbic connections. We have found that all projections from areas TEO and TE to limbic structures are secure in their adult locations in the infant, including those from areas TEO and TE to $\mathrm{L}$. In addition, all limbic inputs to areas TEO and TE that exist in adult monkeys are also present in infant monkeys. However, in addition to these adultlike projections, we also observed a transient projection in the infant from area TEO to LB of the amygdala. This projection was found in the 3 cases with WGA-HRP injections and in both cases with ${ }^{3} \mathrm{H}-\mathrm{AA}$ injections.

Inferior temporal-cortical connections. The results from our anterograde data indicate that all cortical projections from areas TEO and TE that are present in adult monkeys are also present in infant monkeys. However, in addition to these adultlike projections, transient projections also exist in the infant. These transient projections include those from area TE to parahippocampal areas TF and TH as well as to perirhinal area 35 , and from area TEO to area TF. In addition to these transient projections, which become totally eliminated in the adult, there also exist projections in the infant whose terminal fields become more restricted in the adult. For example, the projection from area TE to perirhinal area 36 is considerably more extensive in the infant compared to the adult. Moreover, the projection from both areas TEO and TE to the superior temporal sulcus extends farther dorsally in the infant than in the adult. Thus, even projections to the appropriate target field become more limited in the course of development.

The results from our retrograde data indicate that the regions containing labeled cells in the infants were remarkably similar to the regions containing labeled cells in the adults. This was true after both TEO and TE injections. Because the anterograde labeling in the infant was far more widespread than in the adult but the retrograde labeling was not, the retraction and elimination of connections during development holds only for outputs from area TEO and TE and not for inputs to these cortical 


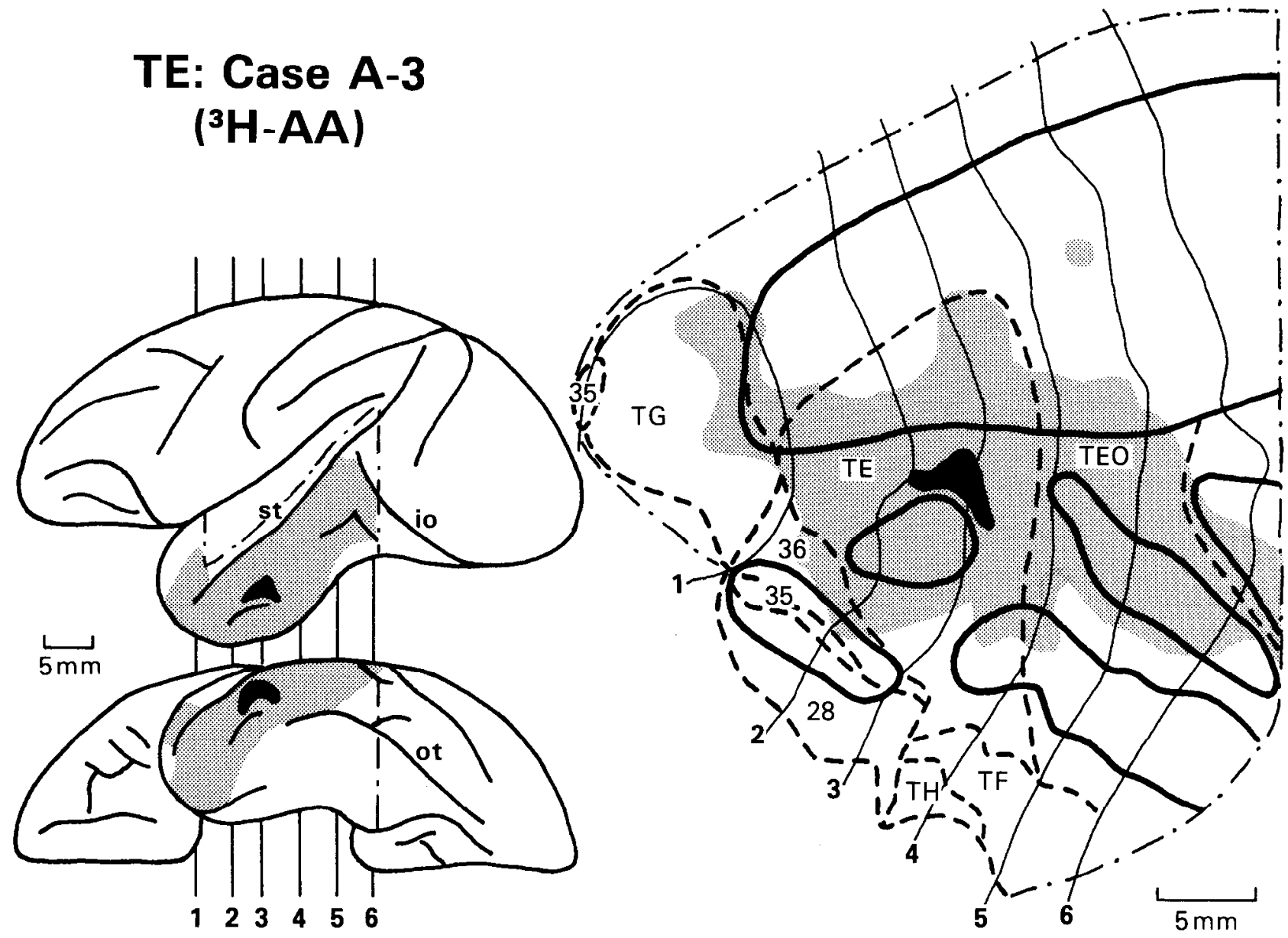

Figure 13. Case A-3: distribution of anterogradely labeled terminals following ${ }^{3} \mathrm{H}-\mathrm{AA}$ injection in area TE of an adult monkey. All conventions are as in Figures 5 and 6.

areas. Is it possible that this finding reflects greater sensitivity of the retrograde tracer WGA-HRP than of the anterograde tracer ${ }^{3} \mathrm{H}-\mathrm{AA}$ ? One finding that would tend to support this idea is the fact that we observed somewhat greater retrograde labeling than anterograde labeling even in the infants, though this asymmetry was clearly not as great as in the adults. In order to explain the difference in the extent of anterograde labeling between infants and adults, one would have to hypothesize that the transport of ${ }^{3} \mathrm{H}$-AA is more effective in infants than in adults. This does not appear to be the case, however, because the anterograde labeling in the amygdala after area TE injections was identical in the infants and adults. Furthermore, Dehay et al. (1986) reported weaker anterograde labeling in infants than in adults after cortical injections of WGA-HRP. We therefore believe that the more widespread anterograde labeling in infants than in adults is not due to differential sensitivity of infants and adults to the anterograde and retrograde tracers. Rather, during the course of development, there appears to be both retraction and refinement of projecting axons from areas TEO and TE to medial temporal-lobe structures, such that some target fields are completely eliminated while others become more limited in their extent. The end result is an asymmetry between inputs and outputs of areas TEO and TE in adults, such that the outputs become more restricted.

\section{Laminar organization of cortical connections}

According to the proposed model of hierarchical organization of visual cortical areas, projections from lower-order areas to higher-order ones originate mainly in layer III of cortex and terminate predominantly in layer IV, whereas projections from higher-order areas to lower-order ones originate mainly in layers V/VI of cortex and terminate both above and below layer IV but not in layer IV (Rockland and Pandya, 1979; Maunsell and Van Essen, 1983). The former has been termed "feedforward," and the latter has been termed "feedback." Maunsell and Van Essen (1983) also described a third laminar pattern that was not clearly feedforward or feedback, in that the terminals varied their laminar pattern from one patch to another or the terminals were homogeneously distributed across all layers including layer IV. They termed this type of projection "intermediate" and suggested that it characterizes connections between areas located at the same hierarchical level. Most recently, Felleman and Van Essen (1991) have concluded that a bilaminar pattern of projecting neurons could characterize either feedforward, feedback, or intermediate-type connections, and therefore retrograde data in the absence of anterograde data are inconclusive. While the feedforward projection is obligatory for the functioning of a higher-order area, in that deactivation or removal of a lower- 
Figure 14. Case A-3: distribution of anterogradely labeled terminals following ${ }^{3} \mathrm{H}-\mathrm{AA}$ injection in area TE of an adult monkey. The label is shown (stippling) on selected coronal sections whose locations are indicated on the lateral and ventral views in Figure 13. All conventions are as in Figures 5-7.

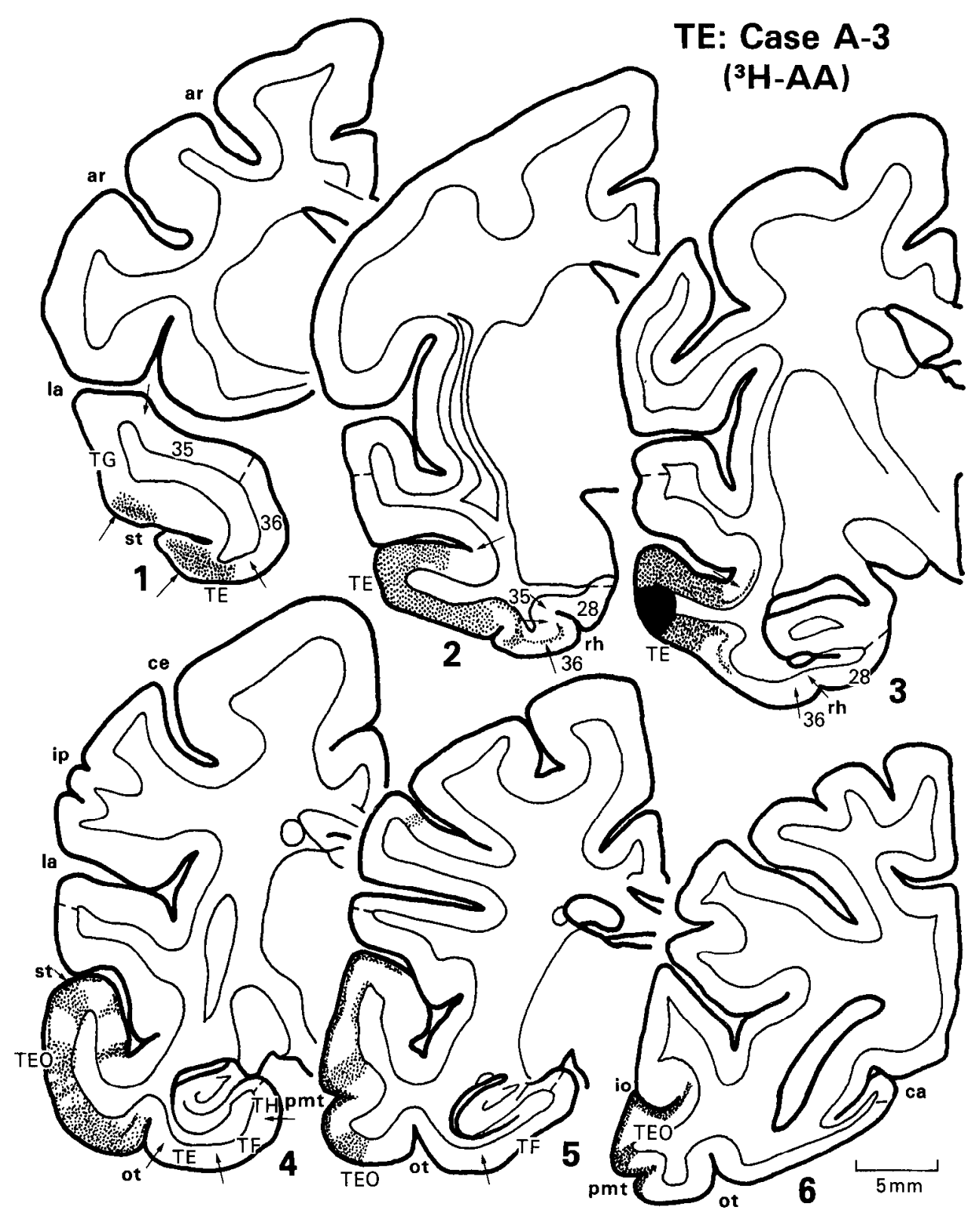

order cortical area (in vision or somesthesis) renders higherorder areas unresponsive (Schiller and Malpeli, 1977; Pons et al., 1987; Girard and Bullier, 1989), the feedback projection is vicwed as modulatory, in that deactivation or removal of a higher-order area does not prevent activation of lower-order ones (Sandell and Schiller, 1982).

Extending the hierarchical model to the connections of areas TEO and TE, our results indicate that, in adult monkeys, area TEO projects forward to area TE, which projects in turn to areas TG and 36. Each of these feedforward projections is reciprocated by a feedback projection. In addition, there appear to be feedback projections from TF and area 35 to both areas TEO and $\mathrm{TE}$, as well as a feedback projection from area 36 to area TEO. With regard to the connections of areas TEO and TE with $\mathrm{TH}$, our results are indeterminate because the cells in area $\mathrm{TH}$ were located about equally in deep and superficial layers and there were no terminals found in area $\mathrm{TH}$ at all. Thus, in adults, area
TE is a higher-order area than TEO but a lower-order area than TG, perirhinal areas, and parahippocampal cortex (with the possible exception of area $\mathrm{TH}$ ).

All of the laminar patterns of connections found in the adults were identical to those found in the infants, with the exception of projections from area TE to perirhinal cortex and from areas TEO and TE to parahippocampal cortex. The projection from area TE to perirhinal cortex differed in 2 ways: First, in area 36 , the projection in adults terminated in layer IV, whereas in infants the projection terminated in layers I and IV. Second, in area 35 , there was no projection in adults, whereas in infants a projection did exist, which terminated again in layers I and IV. Inputs to layers I and IV are not characteristic of exclusively feedforward or feedback projections, but are rather a combination of both. To our knowledge, this particular laminar pattern of termination has not been previously reported and may indicate an immature state of organization. Alternatively, it may 

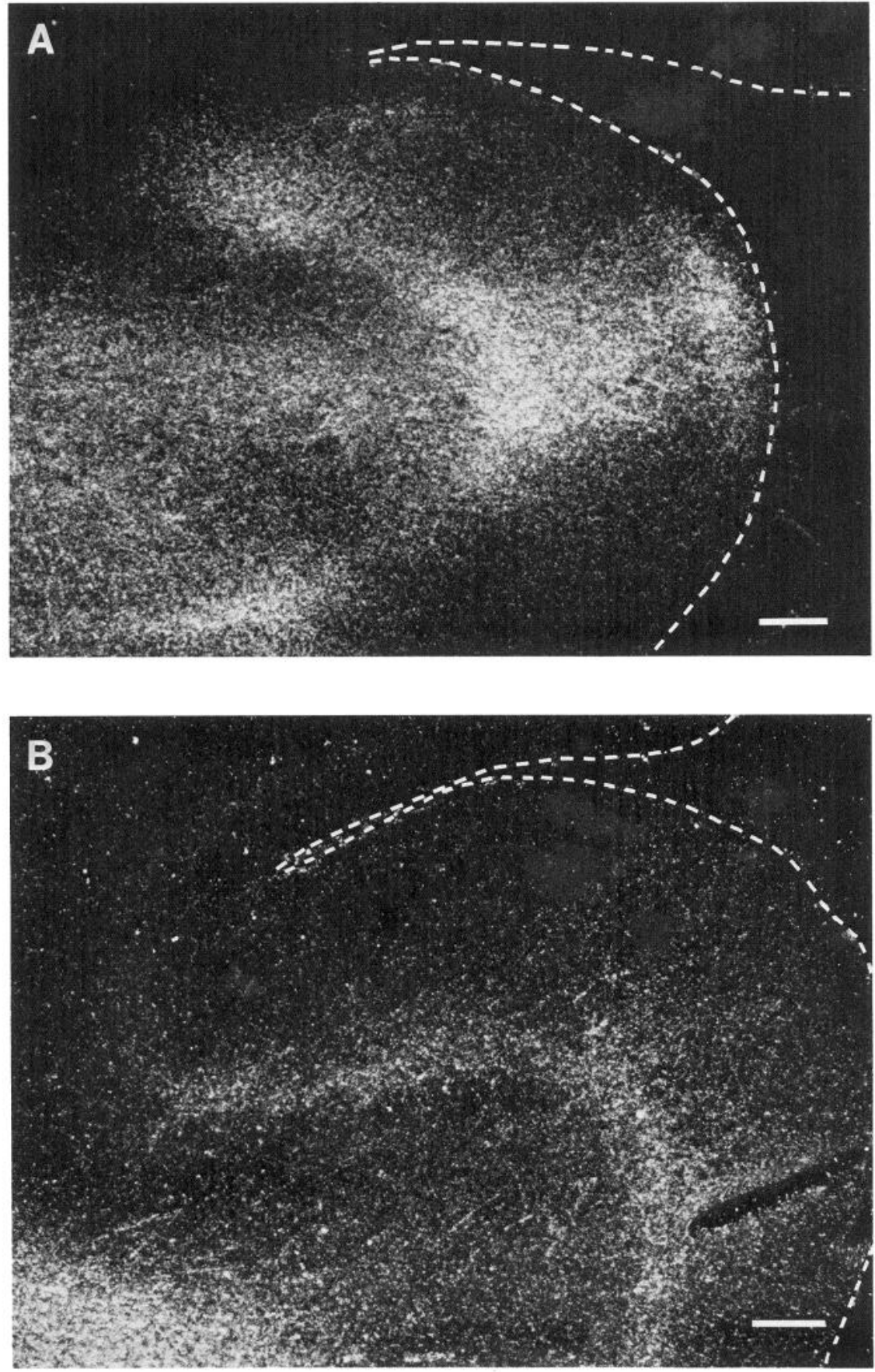

Figure 15. Dark-field photomicrographs illustrating anterogradely labeled terminals in perirhinal cortex following ${ }^{3} \mathrm{H}-\mathrm{AA}$ injections in area TE. $A$, Case I-3; label is located in layers $I$ and IV in the infant. $B$, Case A-3; label is in layer IV only in the adult. For clarity, the edge of the cortex is indicated by a broken line. Scale bars, $250 \mu \mathrm{m}$. qualify as an intermediate-type of connection, indicating that in infants area TE is at the same hierarchical level as perirhinal cortex, whereas in adults area TE is at a lower hierarchical level.

The laminar pattern of projections from areas TEO and TE to parahippocampal areas differed in several ways between infants and adults. First, the only connection between area TF and areas TEO and TE in adults was a feedback projection, such that the cells projecting from area TF to both areas TEO and $\mathrm{TE}$ originated in layers V/VI. In infants, in addition to this feedback projection, there was a feedforward projection from area TEO to area TF, in which terminals were located mainly in layer IV, and a feedback projection from area TE to area TF, in which the terminals were located in all layers except layer
IV. While the former transient connection is consistent with the hierarchical organization of cortical areas found in adults, in that area TEO is lower-order to area TF, the latter transient connection is not, in that area TE is lower-order to area TF in adults, but, in infants, areas TE and TF both send a feedback projection to each other. Second, the only connection between area $\mathrm{TH}$ and areas TEO and TE in adults was an indeterminate type of projection, in that the cells projecting from area $\mathrm{TH}$ originated in both superficial and deep layers and there were no terminals at all in area TH. In infants, in addition to input from both superficial and deep layers of area TH to areas TEO and $\mathrm{TE}$, there was also an intermediate-type projection from area TE to area TH, which terminated in all layers. Thus, the laminar 
A TEO: Case I-2 (WGA-HRP)

Figure 16. Distribution of retrogradely labeled cells following WGA-HRP injections in area TEO. Distribution of cells is shown in shading. $A$, Case $\mathrm{I}-2$, TEO injection in an infant monkey; $B$, case A-2, TEO injection in an adult monkey. All conventions are as in Figures 5 and 6.

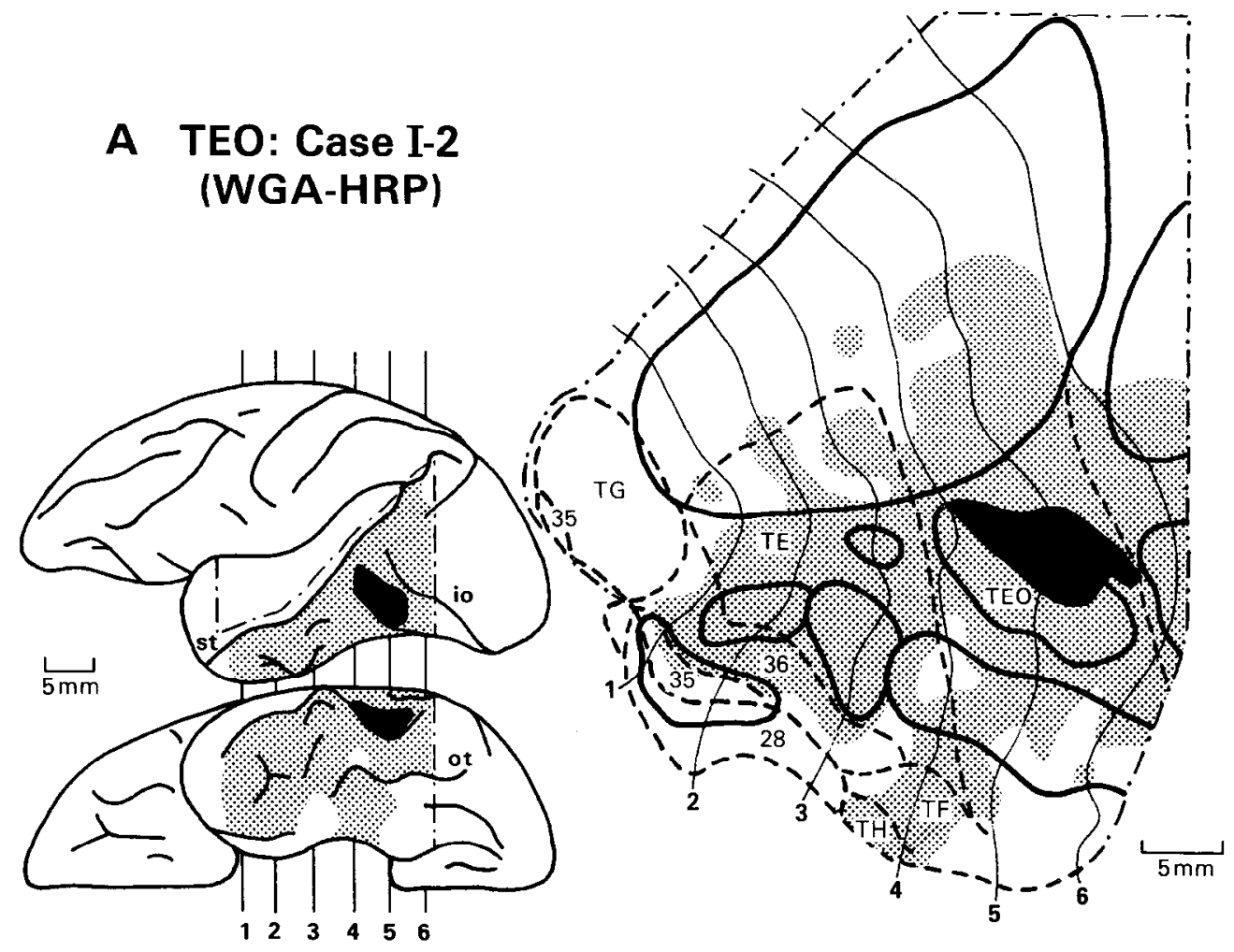

\section{B TEO: Case A-2 (WGA-HRP)}

patterns of the transient projection from area TE to area $\mathrm{TH}$ indicates that these 2 areas are at the same hierarchical level in infants, which may also be true in adults, though our data are insufficient to allow us to conclude this with certainty.

Figure 18 summarizes the feedforward and feedback projections in infant and adult monkeys based on laminar patterns of connections. The figure indicates that, while perirhinal and parahippocampal areas (at least TF) in adults are at a higher hier- archical level than areas TEO and TE, the former areas are at the same hierarchical level as area TE in 1-week-old infants. The adult pattern is achieved by the removal of transient projections from area TE to layer $I$ in areas 35 and 36 and of transient projections from area TE to all layers in area TF. It is not clear whether the elimination of transient projections in these instances results from retraction of collateral branches or from cell death. 


\section{A TE: Case I-2 (WGA-HRP)}

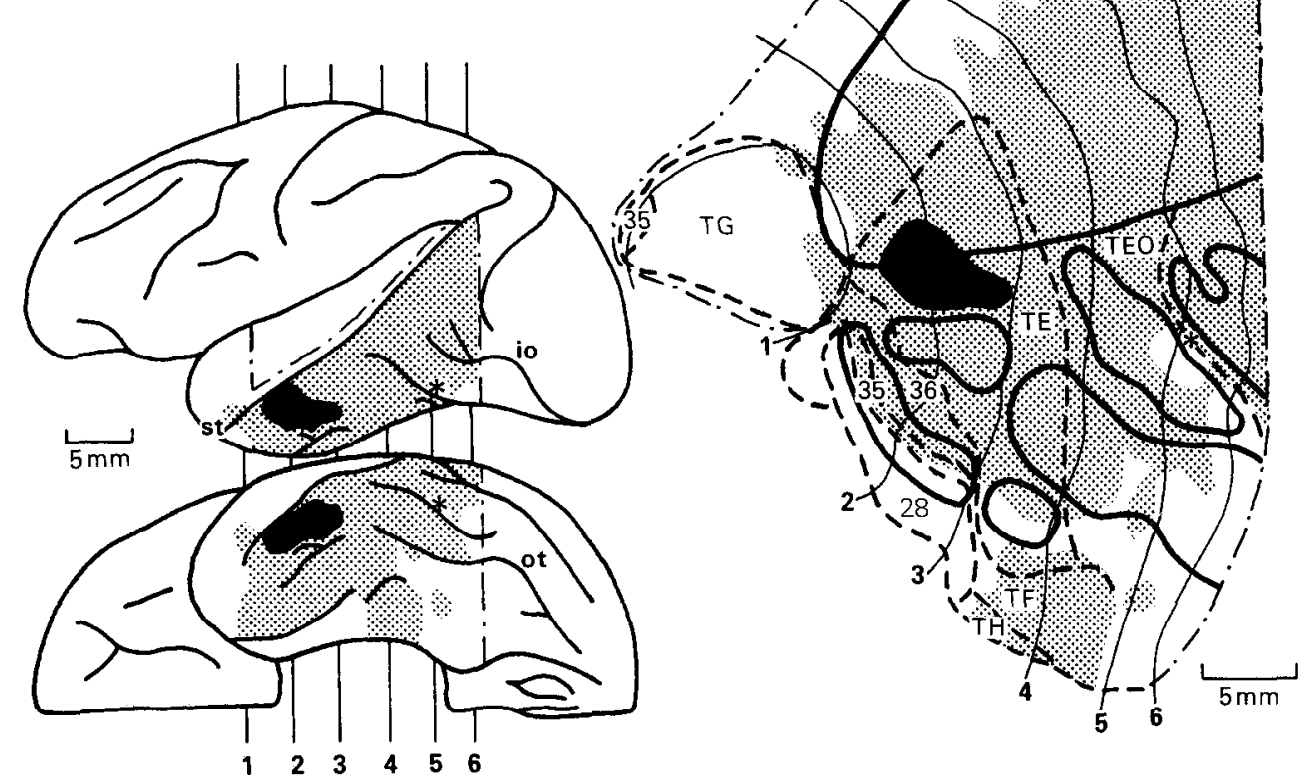

\section{B TE: Case A-2 (WGA-HRP)}
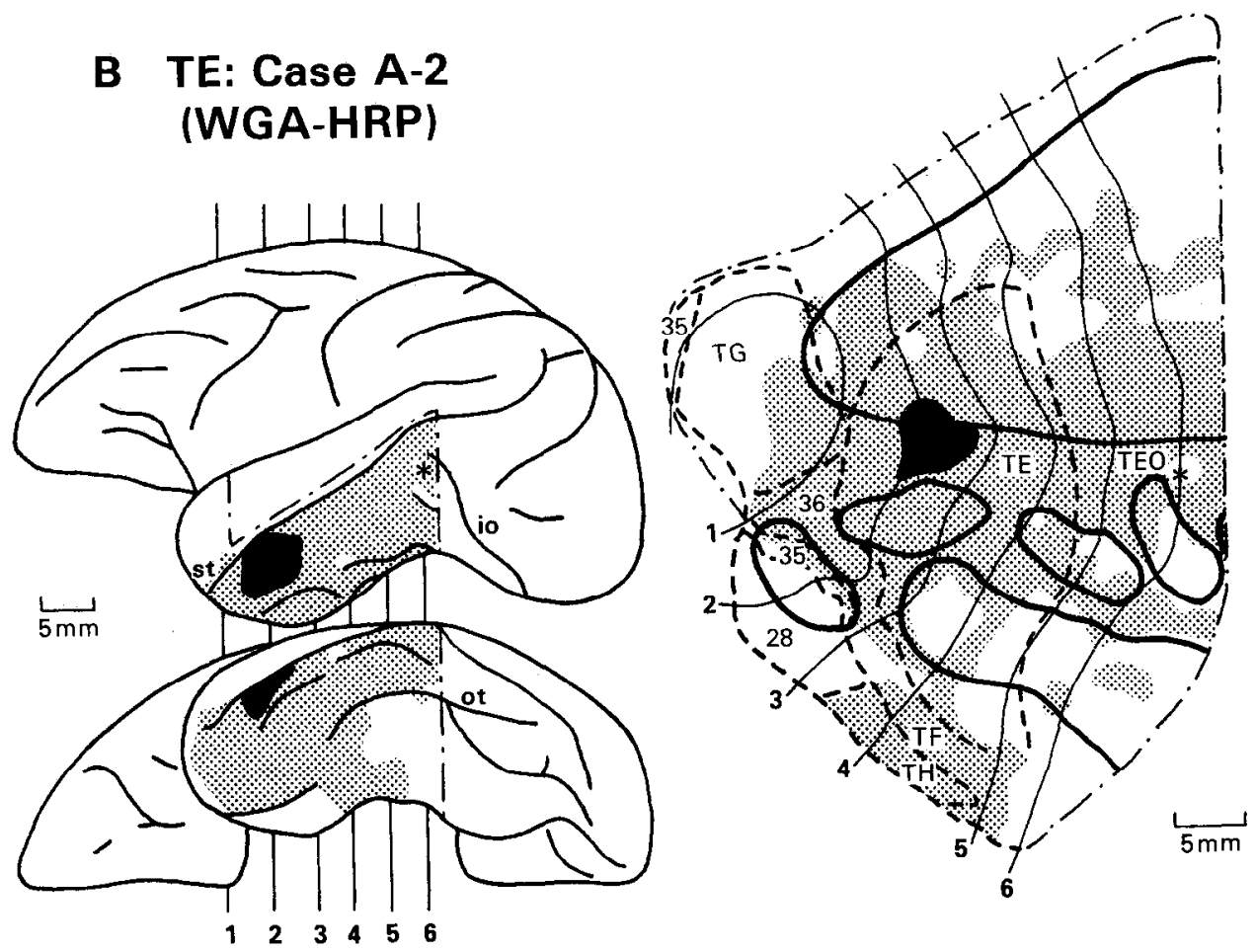

Figure 17. Distribution of retrogradely labcled cells following WGA-HRP injections in area TE. $A$, Case I-2, TE injection in an infant monkey; $B$, case A-2, TE injection in an adult monkey. All conventions are as in Figures 5, 6, and 16.

\section{Significance of transient projections}

Visual recognition memory depends on the sequential processing of visual information by multiple hierarchically organized cortical areas along an occipitotemporal pathway and by the subsequent links of this pathway with the limbic system, particularly with the amygdala, hippocampus, and rhinal cortex (for reviews, see Mishkin and Appenzeller, 1987; Desimone and Ungerleider, 1989; Bachevalier, 1991; but see Zola-Morgan et al., 1989). A loss of visual recognition memory is produced either by removing the limbic structures in this neural circuit or by removing the cortical region in which the visual representation is thought to be stored, that is, area TE. Indeed, in adult monkeys, deficits in visual memory, as measured by delayed nonmatching-to-sample, are equally profound after removal of area TE as after removal of the limbic structures (Mishkin, 1982; Mishkin et al., 1984; Zola-Morgan et al., 1989; Mishkin and Phillips, 1990). This result differs from that found 


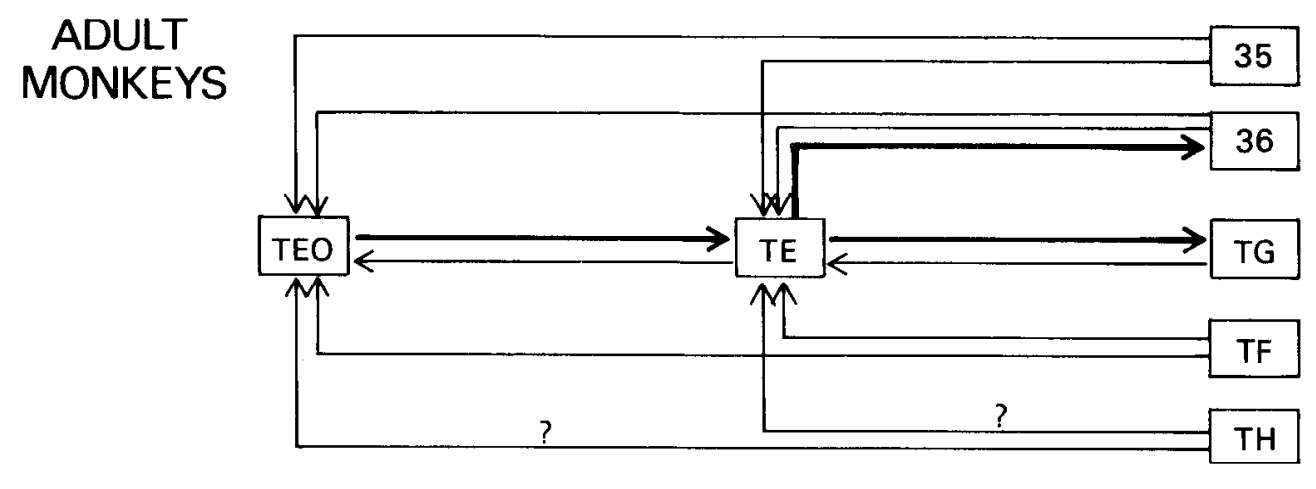

Figure 18. Summary diagram illustrating the feedforward and feedback projections in adult and infant monkeys based on laminar patterns of connections following injections of retrograde and anterograde tracers in areas TEO and TE. Heavy solid lines indicate feedforward projections, i.e., those projections originating mainly in layer III and/or in which terminais are mainly in layer IV. Thin solid lines indicate feedback projections, i.e., those projections originating mainly in layer V/VI and/or in which terminals avoid layer IV. Broken lines denote transient projections that are present in infants but not in adults. Question marks indicate those projections that originate from both layer III and layer V/VI and thus may turn out to be of the intermediate type rather than feedback. As one progresses from left to right on the figure, there is a progression from lower-order to higher-order areas; areas within a column are at the same hierarchical level.

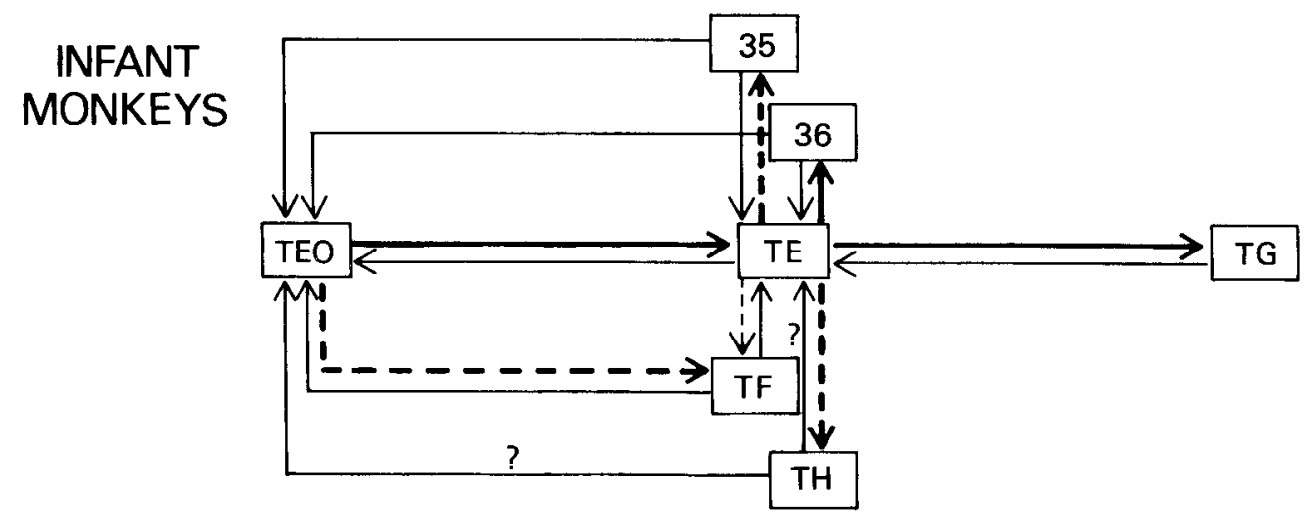

when visual recognition memory has been investigated in infant monkeys. Although removal of limbic structures in infant monkeys yields a marked visual recognition deficit, removal of area TE does not (Bachevalier and Mishkin, 1986). Moreover, this sparing of recognition memory appears to be long lasting (Bachevalier and Mishkin, 1988). Preserved visual recognition ability in monkeys with neonatal TE damage suggests that association areas of cortex, such as area TE, are immature at birth and that lower-order cortical visual areas may possess functional plasticity.

The presence of transient projections from inferior temporal area TEO to both the amygdala and parahippocampal cortex suggests a possible anatomical mechanism to account for the sparing of memory function after removal of area TE in infancy. Early damage to area TE may stabilize normally transient projections, thereby providing a circuit from visual association cortex into the limbic system. Indeed, the maintenance of transient projections after neonatal brain damage has been reported previously (Innocenti and Frost, 1979; Land and Lund, 1979; Caminiti and Innocenti, 1981; Laemle and Labriola, 1982; Bruce and Stein, 1988; Kalil, 1984; Innocenti et al., 1987), though not before in monkeys. However, preliminary results in our laboratory indicate that the transient projection from area TEO to LB of the amygdala in normal infant monkeys is retained in adult monkeys that had received area TE removal in infancy; no such projection is evident in monkeys that had received the same removal in adulthood (Webster et al., 1990). We are now investigating whether the projection from area TEO to parahippocampal cortex, also transient in normal infant monkeys, is similarly retained in adult monkeys that had received area TE lesions in infancy.

\section{Appendix}

Abbreviations

Amygdaloid nuclei

$\mathrm{A}$, anterior nucleus

$\mathrm{AB}$, accessory basal nucleus

$C$, central nucleus

$\mathrm{Co}$, cortical nucleus

$\mathrm{I}$, intercalated nucleus

$\mathrm{L}$, lateral nucleus

LB, lateral basal nucleus

MB, medial basal nucleus

$\mathrm{Me}$, medial nucleus

$\mathrm{P}$, periamygdaloid cortex

\section{Cortical sulci}

amt, anterior middle temporal sulcus

ar, arcuate sulcus

ca, calcarine fissure

ce, central sulcus

co, collateral sulcus

io, inferior occipital sulcus

ip, intraparietal sulcus

la, lateral sulcus

lu, lunate sulcus

orb, orbital sulcus

ot, occipitotemporal sulcus

$p$, principal sulcus

pmt, posterior middle temporal sulcus

rh, rhinal sulcus

st, superior temporal sulcus

\section{Other structures}

$\mathrm{Cd}$, caudate nucleus

$E$, entorhinal cortex

$\mathrm{H}$, hippocampus

Put, putamen

$\mathrm{V}$, ventricle 


\section{References}

Adams CE, Mihailoff GA, Woodward DJ (1983) A transient component of the developing corticospinal tract arises in the visual cortex. Neurosci Lett 36:243-248.

Aggleton JP, Burton MJ, Passingham RE (1980) Cortical and subcortical afferents to the amygdala of the rhesus monkey (Macaca mulatta). Brain Res 190:347-368.

Amaral DG, Bassett JL (1989) Cholinergic innervation of the monkcy amygdala: an immunohistochemical analysis with antisera to choline acetyltransferase. J Comp Neurol 281:337-361.

Amaral DG, Price JL (1984) Amygdalo-cortical projections in the monkey (Macaca fascicularis). J Comp Neurol 230:465-496

Amaral DG, Insausti R, Cowan WM (1987) The entorhinal cortex of the monkey: I. Cytoarchitectonic organization. J Comp Neurol 264: 326-355.

Amaral DG, Avendano C, Benoit R (1989) Distribution of somatostatin-like immunoreactivity in the monkey amygdala. J Comp Neurol 284:293-313.

Bachevalier J (1991) Cortical versus limbic immaturity: relationship to infantile amnesia. In: Minnesota symposium on child psychology, developmental neuroscience (Gunnar MR, Nelson CA, eds), in press. New York: Erlbaum.

Bachevalier J, Mishkin M (1986) Cortical limbic immaturity: relationship to infantile global amnesia in monkeys. Soc Neurosci Abstr 12:10.

Bachevalier J, Mishkin M (1988) Long-term effects of neonatal temporal, cortical and limbic lesions on habit and memory formation in rhesus monkeys. Soc Neurosci Abstr 14:4.

Bachevalier J, Brickson M, Hagger C, Mishkin M (1990) Age and sex differences in the effects of selective temporal lobe lesion on the formation of visual discrimination habits in rhesus monkeys. Behav Neurosci 104:885-889.

Baizer IS, I Ingerleider IG, Desimone R (1991) Organization of visual inputs to inferior temporal and posterior parietal cortex in macaques. J Neurosci 11:168-190.

Berland M, Bullier J, Dehay C, Jaffar-Bandjee Z, Kennedy H (1987) Callosal connections and cytochrome oxidase-staining of visual areas $\mathrm{V} 1$ and V2 in the prenatal monkey (Macaca irus). J Physiol (Lond) 382:95P.

Boussaoud D, Ungerleider LG, Desimone R (1990) Pathways for motion analysis: cortical connections of the medial superior temporal and fundus of the superior temporal visual areas in the macaque. $J$ Comp Neurol 296:462-495.

Boussaoud D, Desimone R, Ungerleider LG (1991) Visual topography of area TEO in the macaque. $J$ Comp Neurol, in press.

Bruce LL, Stein BE (1988) Transient projections from the lateral geniculate to the posteromedial lateral suprasylvian cortex in kittens. J Comp Neurol 278:287-302.

Bunt SM, Lund RD (1981) Development of a transient retino-retinal pathway in hooded and albino rats. Brain Res 211:399-404.

Caminiti R, Innocenti GM (1981) The postnatal development of somatosensory callosal connections after partial lesions of somatosensory areas. Exp Brain Res 42:53-62.

Chow KL, Baumbach HD, Lawson R (1981) Callosal projections of the striate cortex in the neonatal rabbit. Exp Brain Res 42:122-126.

Clarke S, Innocenti GM (1986) Organization of immature intrahemispheric connections. J Comp Neurol 251:1-22.

Cowan WM, Gottleib DI, Hendrickson AE, Price JL, Woolsey JL (1972) The autoradiographic demonstration of axonal connections in the central nervous system. Brain Res 37:21-51.

Cusick CG, I und RD (1982) Modifications of visual callosal projections in rats. J Comp Neurol 212:385-398.

Dehay C, Bullier J, Kennedy H (1984) Transient projections from the fronto-parietal and temporal cortex to areas 17,18 and 19 in the kitten. Exp Brain Res 57:208-212.

Dehay C, Kennedy H, Bullier J (1986) Callosal connectivity of areas $\mathrm{V} 1$ and $\mathrm{V} 2$ in the newborn monkey. $J$ Comp Neurol 254:20-33.

Dehay C, Hein A, Kennedy H (1987) A transient cortical projection to the pyramidal tract in the neonatal ferret. J Physiol (Lond) 382: 96P.

Dehay C, Kennedy H, Bullier J (1988) Characterization of transient cortical projections from auditory, somatosensory, and motor cortices to visual areas 17,18 , and 19 in the kitten. J Comp Neurol 272:6889.
Desimone R, Ungerleider LG (1989) Neural mechanisms of visual perception in monkeys. In: Handbook of neuropsychology, Vol 2 (Boller R, Grafman J, eds), pp 267-299. Amsterdam: Elsevier.

Desimone R, Flemming J, Gross CG (1980) Prestriate afferents to inferior temporal cortex: an HRP study. Brain Res 184:41-55.

Distel H, Hollander H (1980) Autoradiographic tracing of developing subcortical projections of the occipital regions in fetal rabbits. J Comp Neurol 192:505-518.

Felleman DJ, Van Essen DC (1991) Distributed hierarchical processing in primate cerebral cortex. Cereb Cortex 1, in press.

Feng JZ, Brugge JF (1983) Postnatal development of auditory callosal connections in the kitten. J Comp Neurol 214:416-426

Gattass R, Gross CG (1981) Visual topography of striate projection zone (MT) in posterior superior temporal sulcus of the macaque. $J$ Neurophysiol 46:621-638.

Gibson AR, Hansma DI, Houk JC, Robinson FR (1984) A sensitive low artifact TMB procedure for the demonstration of WGA-HRP in the CNS. Brain Res 298:235-241.

Girard P, Bullier J (1989) Visual acuity in area V2 during reversible inactivation of area 17 in the macaque monkey. J Neurophysiol 62: $1287-1302$.

Innocenti GM (1981) Growth and reshaping of axons in the establishment of visual callosal connections. Science 212:824-827.

Innocenti GM, Caminiti R (1980) Postnatal shaping of callosal connections from sensory areas. Exp Brain Res 38:381-394.

Innocenti GM, Clarke S (1984) Bilateral transitory projection to visual areas from auditory cortex in kittens. Dev Brain Res 14:143-148.

Innocenti GM, Frost DO (1979) Effects of visual experience on the maturation of the efferent system to the corpus callosum. Nature 280 231-234.

Innocenti GM, Fiore L, Caminiti R (1977) Exuberant projection into the corpus callosum from the visual cortex of newborn cats. Neurosci Lett $4: 237-242$

Innocenti GM, Berbel P, Melzer P (1987) Stabilization of transitory cortico-cortical projections following lesions provoked by neonatal ibotenic acid injections. Neuroscience 22:680P.

Insausti R, Amaral DG, Cowan WM (1987) The entorhinal cortex of the monkey: II. Cortical afferents. J Comp Neurol 264:356-395.

Ivy GO, Killackey HP (1981) The ontogeny of the distribution of callosal projection neurons in the rat parietal cortex. J Comp Neurol 195:367-389.

Ivy GO, Killackey HP (1982) Ontogenetic changes in the projections of neocortical neurons. J Neurosci 2:735-743.

Ivy GO, Akers RM, Killackey HP (1979) Differential distribution of callosal projection neurons in the neonatal and adult rat. Brain Res 173:532-537.

Iwai E, Mishkin M (1969) Further evidence on the locus of the visual area in the temporal lobe of the monkey. Exp Neurol 25:585-594.

Iwai E, Yukie M (1987) Amygdalofugal and amygdalopetal connections with modality-specific visual cortical areas in macaques $(\mathrm{Ma}$ caca fuscata, $M$. mulatta, and $M$. fascicularis). J Comp Neurol 261: 362-387.

Iwai E, Yukie M (1988) A direct projection from hippocampal field CA1 to ventral area TE of inferotemporal cortex in the monkey. Brain Res 444:397-401.

Iwai E, Yukie M, Suyama H, Shirakawa S (1987) Amygdalar connections with middle and inferior temporal gyri of the monkey. Neurosci Lett 83:25-29.

Jones EG, Powell TPS (1970) An anatomical study of the converging sensory pathways within the cerebral cortex of the monkey. Brain 93 . 793-820.

Kalil RE (1984) Removal of visual cortex in the cat: effects on the morphological development of the retino-geniculo-cortical pathway. In: Development of visual pathways in mammals (Stone J, Dreher B, Rapaport D, eds), pp 257-274. New York: Liss.

Killackey HP, Chalupa LM (1986) Ontogenetic change in the distribution of callosal projection neurons in the postcentral gyrus of the fetal rhesus monkey. J Comp Neurol 244:331-348.

Laemle LK, Labriola AR (1982) Retinocollicular projections in the neonatal rat: an anatomical basis for plasticity. Dev Brain Res 3:317322.

Land PW, Lund RD (1979) Development of the rat's uncrossed retinotectal pathway and its relation to plasticity studies. Science 149 . 1506-1507.

Maunsell JHR, Van Essen DC (1983) The connections of the middle 
temporal visual area (MT) and their relationship to a cortical hierarchy in the macaque monkey. J Neurosci 3:2563-2586.

Mishkin M (1982) A memory system in the monkey. Philos Trans R Soc Lond [Biol] 289:85-95.

Mishkin M, Appenzeller T (1987) The anatomy of memory. Sci Amer 256:80-89.

Mishkin M, Phillips RR (1990) A corticolimbic memory path revealed through its disconnection. In: Brain circuits and functions of the mind: essays in honor of Roger W. Sperry (Trevarthen C, ed), pp 196-210. Cambridge: Cambridge UP.

Mishkin M, Malamut B, Bachevalier J (1984) Memories and habits: two neural systems. In: Neurobiology of learning and memory (Lynch G, McGaugh JL, Weinberger MN, eds), pp 65-77. New York: Guiford.

O'Leary DDM, Stanfield BB, Cowan WM (1981) Evidence that the early postnatal restriction of the cells of origin of the callosal projection is due to the elimination of axon collaterals rather than to the death of neurons. Dev Brain Res 1:607-617.

O'Leary DDM, Gerfen CR, Cowan WM (1983) The development and restriction of the ipsilateral retinofugal projection in the chick. Dev Brain Res 10:93-109.

Pons TP, Garraghty PE, Friedman DP, Mishkin M (1987) Physiological evidence for serial processing in somatosensory cortex. Science 237:417-420.

Rockland KS, Pandya DN (1979) Laminar origins and terminations of cortical connections of the occipital lobe in the rhesus monkey. Brain Res 179:3-20.

Rosene DL, Roy NJ, Davis BJ (1986) A cryoprotection method that facilitates cutting frozen sections of whole monkey brains for histological and histochemical processing without freezing artifact. J Histochem Cytochem 34:1301-1315.

Sandell JH, Schiller PH (1982) Effect of cooling area 18 on striate cortex cells in the squirrel monkey. J Neurophysiol 48:38-48.

Schiller PH, Malpeli JG (1977) The effect of striate cortex cooling on area 18 cells in the monkey. Brain Res 126:366-369.

Seltzer B, Pandya DN (1976) Some cortical projections to the parahippocampal area in the rhesus monkey. Exp Neurol 50:146-160.

Shiwa T (1987) Corticocortical projections to the monkey temporal lobe with particular reference to the visual processing pathways. Arch Ital Biol 125:139-154.

Stanfield BB (1984) Postnatal reorganization of cortical projections: the role of collateral elimination. Trends Neurosci 7:37-41.

Stanfield BB, O'Leary DDM (1985) The transient cortico-spinal pro- jection from the occipital cortex during the postnatal development of the rat. J Comp Neurol 238:236-248.

Stanfield BB, O'Leary DDM, Fricks C (1982) Selective collateral elimination in early postnatal development restricts cortical distribution of rat pyramidal tract neurons. Nature 298:371-373.

Stanfield BB, Nahin BR, O'Leary DDM (1987) A transient postmamillary component of the rat fornix during development: implications for interspecific differences in mature axonal projections. J Neurosci 7:3350-3361.

Tolbert DL, Panneton WM (1983) Transient cerebrocerebellar projections in kittens: postnatal development and topography. J Comp Neurol 221:216-228.

Turner BH, Mishkin M, Knapp M (1980) Organization of the amygdalopetal projections from modality specific cortical association areas in the monkey. J Comp Neurol 191:515-543.

Ungerleider LG, Desimone R (1986) Cortical projections of visual area MT in the macaque. J Comp Neurol 248:190-222.

Van Hoesen GW (1980) The cortico-cortical projections of the posterior parahippocampal area in the rhesus monkey. Anat Rec 196: 195A.

Van Hoesen GW (1982) The parahippocampal gyrus: new observations regarding its cortical connections in the rhesus monkey. Trends Neurosci 5:345-350.

Van Hoesen GW, Pandya D (1975) Some connections of the entorhinal (area 28) and perirhinal (area 35) cortices of the rhesus monkey. I. Temporal lobe afferents. Brain Res 95:1-24.

von Bonin G, Bailey P (1947) The neocortex of Macaca mulatta. Urbana, IL: University of Illinois.

Webster MJ, Bachevalier J, Ungerleider LG (1988) Plasticity of visual memory circuits in developing monkeys. Soc Neurosci Abstr 14:1.

Webster MI, Ungerleider LG, Bachevalier J (1989) Projections from inferior temporal cortex to widespread perirhinal areas in infant monkeys. Soc Neurosci Abstr 15:342.

Webster MJ, Ungerleider LG, Bachevalier J (1990) Lesions of inferior temporal area TE in infant monkeys produce reorganization of cortico-amygdalar projections. Soc Neurosci Abstr 16:618.

Wise SP, Jones EG (1976) The organization and postnatal development of the commissural projection of the rat somatic sensory cortex. J Comp Neurol 168:313-344.

Zola-Morgan S, Squire LK, Amaral DG, Suzuki WA (1989) Lesions of perirhinal and parahippocampal cortex that spare the amygdala and hippocampal formation produce severe memory impairment. J Neurosci 9:4355-4370. 